MUSTAPHÁ AMAD NETO

\title{
ESTUDO DA PADRONIZAÇÃO PARA A DETERMINAÇÃO DE PONTOS CEFALOMÉTRICOS UTILIZADOS NA CEFALOMETRIA RADIOLÓGICA
}


Mustaphá Amad Neto

\section{Estudo da padronização para a determinação de pontos cefalométricos utilizados na cefalometria radiológica}

Tese apresentada à Faculdade de Odontologia da Universidade de São Paulo, para obter o título de Doutor pelo Programa de PósGraduação em Odontologia.

Área de Concentração: Diagnóstico Bucal; subárea Radiologia.

Orientador: Prof. Dr. Israel Chilvarquer

São Paulo 


\section{FOLHA DE APROVAÇÃO}

Amad Neto M. Estudo da padronização para a determinação de pontos cefalométricos utilizados na cefalometria radiológica [ Tese de Doutorado ]. São Paulo: Faculdade de Odontologia da USP; 2004.

São Paulo,

\section{Banca Examinadora}

1) $\operatorname{Prof}(a)$. $\operatorname{Dr}(a)$.

Titulação:

Julgamento:

Assinatura:

2) $\operatorname{Prof}(a)$. $\operatorname{Dr}(a)$.

Titulação:

Julgamento:

Assinatura:

3) $\operatorname{Prof}(a)$. $\operatorname{Dr}(a)$.

Titulação:

Julgamento:

Assinatura:

4) $\operatorname{Prof}(a) \cdot \operatorname{Dr}(a)$.

Titulação:

Julgamento:

Assinatura:

5) $\operatorname{Prof}(a) . \operatorname{Dr}(a)$.

Titulação:

Julgamento:

Assinatura: 


\section{DEDICATÓRIA}

Dedico este trabalho "in memoriam" ao meu pai, que foi um exemplo, e o norte da minha vida.

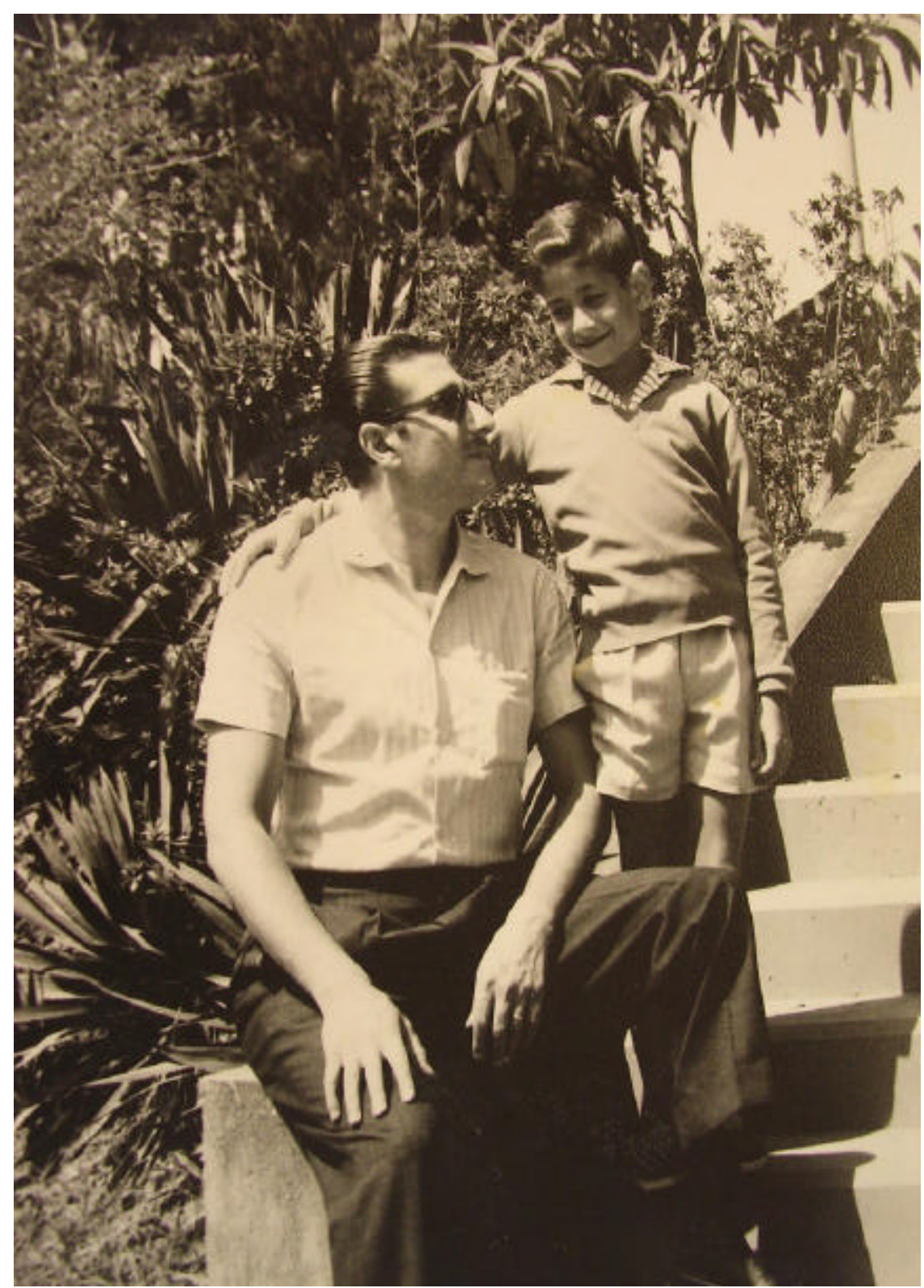




\section{AGRADECIMENTOS}

Ao Prof. Dr. Jurandyr Panella pela oportunidade de participar do programa do curso de Pós-Graduação da Faculdade de Odontologia da Universidade de São Paulo.

Ao Prof. Dr. Israel Chilvarquer pela orientação e dedicação na elaboração deste trabalho.

Ao Prof. Dr. Daniel Korytnick pela colaboração e amizade prestada desde o princípio de minha vida acadêmica.

Aos colegas do curso de Pós-Graduação da Universidade de São Paulo pelo companheirismo demonstrado.

Aos funcionários do departamento de Radiologia da Faculdade de Odontologia da Universidade de São Paulo pelos serviços prestados.

Aos funcionários da Biblioteca da Faculdade de Odontologia da Universidade de São Paulo pela cuidadosa revisão deste trabalho.

A todos aqueles que direta ou indiretamente colaboraram com a realização deste trabalho.

A minha família que durante sempre estiveram ao meu lado. 
Amad Neto M. Estudo da padronização para a determinação de pontos cefalométricos utilizados na cefalometria radiológica [Tese de Doutorado ]. São Paulo: Faculdade de Odontologia da USP; 2004

\section{RESUMO}

O objetivo nesta pesquisa foi o de avaliar quantitativamente as variações na determinação de 7 pontos cefalométricos e analisar o quanto que estes erros podem influenciar no planejamento e progressão da terapêutica ortodôntica. Foram utilizados 14 crânios macerados onde fora colocadas esferas metálicas para a demarcação dos pontos cefalométricos escolhidos. Estes crânios foram radiografados com e sem as esferas metálicas, e as grandezas cefalométricas avaliadas estatisticamente. Os resultados mostraram que a média de erro na localização dos pontos foi de $57,5 \%$ e que este desvio em termos numéricos podem levar a equívocos de planejamento que podem comprometer seriamente o resultado do tratamento com desvios em algumas medidas cefalométricas de até $4 \mathrm{~mm}$. As mensurações relacionadas aos pontos espinha nasal anterior, pogonio e gônio, foram as que tiveram maior reprodutibilidade, porém, as medidas cefalométricas relacionadas ao ponto A mostraram que as diferenças encontradas então em torno de 4,3mm, e que a avaliação do comprimento mandibular obtida pela localização do ponto condílio, também gerou diferenças de $2,8 \mathrm{~mm}$ em média, alterando assim substancialmente as avaliações para diagnóstico e tratamento ortodôntico e cirúrgico.

Palavras-Chave: Telerradiografia - Análise Cefalométrica - Identificação de pontos cefalométricos 
Amad Neto M. Standardization for the determination of cephalometric landmarks used in radiological cephalometric analysis [Tese de Doutorado]. São Paulo: Faculdade de Odontologia da USP; 2004.

\section{ABSTRACT}

The aim of this study were to evaluate quantitatively the variations on the determination of 7 cephalometric landmarks and to analyze how these differences may influence the planning and outcome of the orthodontic treatment.

Small steel balls were glued on specific sites of 14 dry skulls to represent the true anatomical landmarks. The skulls were radiographed with and without the steel balls, and the cephalometric values were submitted to statistical analysis. Results showed that the error in the localization of the landmarks was in average $57,5 \%$. This high deviation, that reaches up to $4 \mathrm{~mm}$ in certain cephalometric measurements, could lead to errors in treatment planning and compromise the result of any orthodontic treatment. Measurements of the Anterior Nasal Spine, Pogonion and Gonion showed the highest reproducibility, while point $A$ showed the lowest $(4,3 \mathrm{~mm})$. The evaluation of the mandibular length through the identification of Condyle also showed high discrepancies $(2,8 \mathrm{~mm})$, which may alter the evaluations for orthodontic and/or surgical diagnosis and treatment.

Key-words: Cephalometric radiograph - Cephalometric analysis - Landmark identification 


\section{LISTA DE ILUSTRAÇÕES}

Figura 4.1 - A figura demonstra o traçado cefalométrico com os pontos a serem utilizados na avaliação

Figura 4.2 - Traçado com os pontos cefalométricos marcados sobre a radiografia do crânio.

Figura 4.3 - Traçado com os pontos metálicos marcados sobre a radiografia do crânio

Figura 4.4 - Utilizamos o traçado, com sobreposição dos pontos cefalométricos e pontos metálicos, para mensuração das diferenças de localização dos pontos

Figura 4.5 - Fotografia do crânio adaptado ao cefalostato no aparelho Quint Sectograph..

Figura 4.6 - Demonstração da marcação do ponto metálico na região do nasio

Figura 4.7 - Demonstração da marcação do ponto metálico condílio na região do côndilo

Figura 4.8 - Aspecto da radiografia com os pontos cefalométricos identificados .35

Figura 4.9 - Aspecto da radiografia com os marcadores metálicos nos pontos cefalométricos

Figura 5.10 -Curva de avaliação do método 


\section{LISTA DE TABELAS}

Tabela 5.1 - Resultados fornecidos pela amostra piloto 38

Tabela 5.2 - Possíveis fatores para $n 1$ .38

Tabela 5.3 - Possíveis valores para n2, assumindo $\sigma=2,31$ 39

Tabela 5.4 - Valores das probabilidades do erro absoluto cometido, utilizando o método em avaliação ser maior do que o erro máximo admissível

Tabela 6.1 - Tabela de medidas utilizadas no projeto piloto .45

Tabela 6.2 - Demonstração das medidas entre o ponto condílio e o ponto A, em radiografias com pontos cefalométricos e pontos marcados. 46

Tabela 6.3 - Demonstração das medidas entre o ponto A e naso perpendicular em radiografias com pontos cefalométricos e pontos marcados. 47 


\section{LISTA DE ABREVIATURA E SIGLAS}

- N (Násio): Ponto mais anterior na sutura fronto-nasal;

- Po (Pório): Ponto mais alto no contorno superior da imagem do meato auditivo externo;

- Or (Orbital): Ponto que representa a porção mais inferior da órbita;

- ENA (Espinha nasal anterior): Ponto mais anterior no soalho da fossa nasal;

- ENP (Espinha nasal posterior): Ponto mais posterior no soalho da fossa nasal;

- PTM (Ptérigo maxilar): Ponto eqüidistante mais superior e mais posterior do contorno da fossa ptérigo-maxilar;

- A : Ponto mais profundo da concavidade do osso alveolar vestibular, na região anterior da maxila;

- Pg (Pogônio): Ponto mais anterior na superfície externa da cortical anterior da sínfise mentoniana;

- Gn (Gnátio): Ponto eqüidistante a dois pontos, o mais inferior e o mais posterior, na superfície externa da cortical anterior da sínfise mandibular;

- Me (Mentoniano): Ponto mais inferior àsuperfície externa da cortical anterior da sínfise mandibular;

- Go (Gônio): Ponto na superfície externa da cortical do ângulo goniano, eqüidistante do ponto mais inferior e do mais posterior dessa região;

- Co (Condílio): Ponto eqüidistante a dois pontos, o mais superior e o mais posterior na cabeça da mandíbula; 


\section{SUMÁRIO}

1 INTRODUÇÃO...........................................................................11

2 REVISÃO DA LITERATURA............................................................13

3 PROPOSIÇÃO...........................................................................27

4 MATERIAL E MÉTODOS...............................................................28

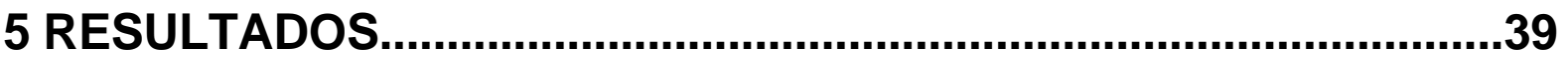

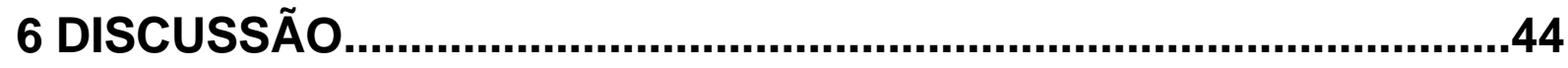

7 CONCLUSÕES..........................................................................55

REFERÊNCIAS............................................................................57

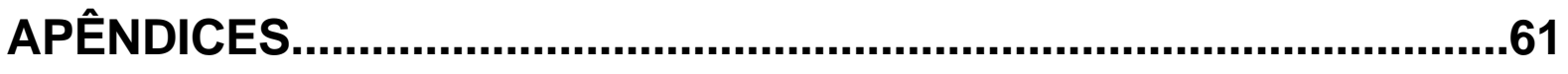

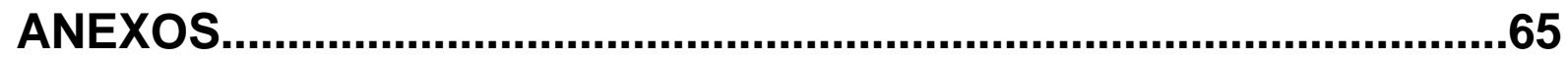




\section{INTRODUÇÃO}

Nos primórdios da ortodontia, a primeira preocupação era o alinhamento dos dentes individualmente; de modo especial, na arcada superior em função da estética. Em segundo plano, vinha a prevenção de cáries, devido aos pontos de contato interproximais inadequados (RICKETTS 1970).

Quando outros fatores passaram a ser considerados, o diagnóstico começou a ficar mais elaborado, exigindo melhor documentação.

Broadbent (1931) estabeleceu o uso da cefalometria, como meio de diagnóstico moderno. Desde então, este método vem sendo utilizado como parte dos registros, para auxiliar o diagnóstico e o planejamento dos tratamentos ortodônticos.

A abundância de informações radiográficas foi organizada em análises cefalométricas. Estas foram usadas, para classificar os casos de acordo com o tipo de má oclusão, para definir o grau de desvio da normalidade e para medir a extensão das mudanças ocorridas durante o tratamento ou durante o período de observação (BAUMRIND; FRANTZ, 1971).

As análises cefalométricas têm sido tradicionalmente realizadas por meio de traçados sobre as telerradiografias laterais; porém, a determinação dos pontos cefalométricos, usados para a determinação das medidas cefalométricas, tem se 
mostrado não reprodutível, quando os pontos cefalométricos são comparados nos estudos de diversos observadores ( STEINER, 1959).

A não reprodutibilidade do método direto é conseqüência da falta de precisão na determinação dos pontos cefalométricos, bem como dos erros de medida por instrumentos manuais (régua compasso, lápis) (HOUSTON, 1982).

Inúmeros trabalhos foram realizados para avaliar as medidas cefalométricas obtidas manualmente ou por meio de imagens digitalizadas por computador. Sempre a margem de erro se mostrou significante; em especial, devido æ̀s diferenças na localização dos pontos cefalométricos (AMAD NETO, 1998).

Até que ponto a imprecisão das medidas pode levar a uma conduta terapêutica equivocada é uma discussão que nos leva a pensar que, para determinados tipos de pacientes, esse erro não alterará o posicionamento espacial das estruturas ósseas. Portanto, não vindo alterar substancialmente, as medidas cefalométricas.

Contudo, quando esses erros vêm acompanhados de uma alteração espacial, principalmente da postura mandibular, o diagnóstico e o planejamento estarão sensivelmente comprometidos.

O objeto de estudo neste trabalho, é a verificação da acuracia na determinação dos pontos cefalométricos, procurando comparar a localização de pontos cefalométricos diretamente sobre as estruturas ósseas e a correspondente localização radiográfica deles. 


\section{REVISÃO DA LITERATURA}

Após a introdução do cefalostato e a padronização da distância foco-filme, publicadas por Broadbent em 1931, foram possíveis a redução de variáveis em cefalometria e a comparação dos resultados clínicos e experimentais em todo o mundo. Assim que surgiram as primeiras análises cefalométricas, tornou-se necessária uma tentativa de padronização para diminuir os possíveis erros técnicos.

Rosenfeld ${ }^{1}$, em 1987 (apud de ADAMS, 1940) escreveu sobre as distorções resultantes da variação de distância entre o tubo de $\mathrm{RX}$, (objetivo a ser radiografado) e o filme. Mostrou também, que as medidas cefalométricas de maior confiabilidade eram as lineares, em comparação com as angulares, uma vez que a margem de erro na leitura daquela era menor do que na leitura destas.

Jeweff $^{2}$ (apud de ADAMS, 1940) utilizou cem casos e estimou em 5\% o aumento da sela túrcica, como resultante de distorção a uma distância de 1,5m. Mortimar, Levine e Rowe ${ }^{3}$ (1937), (apud de ADAMS, 1940), mostraram um aumento de $4 \%$ a $6 \%$, no tamanho do crânio, quando o filme foi afastado $75 \mathrm{~cm}$.

Avaliando as tabelas de distorções, esses autores concluíram que é necessário usar escalas corretivas nas mensurações cefalométricas ao invés de fórmulas matemáticas de correção para cada ponto, pois estas estão sujeitas a maior margem de erro.

\footnotetext{
${ }^{1}$ Rosenfeld

${ }^{2}$ Jeweff
} 
Downs (1948) fez estudos com radiografias de 20 pacientes entre 12 e 17 anos, sendo 10 do sexo masculino e 10 do sexo feminino. Avaliou o padrão do esqueleto cefálico independentemente do processo alveolar e dos dentes, bem como a relação dos dentes e do processo alveolar com o esqueleto facial.

Steiner (1953) preconizava que um cefalograma com menor número de linhas e ângulos poderia diminuir a quantidade de erros no traçado e na interpretação, mesmo quando feito por diferentes profissionais. Defendia o seu método, afirmando que as linhas, em seu cefalograma, estavam mais próximas das regiões a serem tratadas pelo ortodontista; portanto, eram de visualização e compreensão mais adequadas.

Brodie (1954) enfatizou a necessidade de fazer uso de registros, tanto de modelo de estudo como radiográfico e, principalmente, cefalométrico, para a análise dos objetivos do tratamento ortodôntico.

Holdaway (1956) avaliou a diferença entre os pontos A e B, antes e após o tratamento, para verificar as diferenças, mesmo quando as medidas eram realizadas por diferentes profissionais. Os resultados mostraram que não houve diferença estatisticamente significante para essas medidas, quando comparadas com médias angulares dos ângulos SNA (ângulo formado entre a linha SN e a linha NA) e SNB (ângulo formado entre a linha SN e a linha NB).

Riedel (1957) usou os resultados do trabalho de Holdaway (1956) sobre as relações dentofaciais e observou que, quando vários profissionais realizaram traçados cefalométricos, houve menor discrepância de resultados nas medidas feitas sobre os tecidos duros do que nas que foram feitas sobre os tecidos moles do perfil. 
Foi realizado o primeiro workshop, Bolton Fund Head Quarters (1958) sobre cefalometria, com o objetivo de padronizar a localização dos pontos cefalométricos e determinar quais os planos, linhas e ângulos que deveriam ser analisados em relação ao menor índice de distorção, tanto na radiografia quanto na interpretação dos pontos de reparo anatômico.

Steiner (1959) falou sobre a dificuldade de localização de pontos usados normalmente em cefalometrias e salientou que diversos profissionais podiam fazer traçados e medidas diferentes, relacionados aos mesmos pontos dos mesmos pacientes. De qualquer modo, enfatiza a necessidade da cefalometria, com o intuito de analisar problemas e determinar soluções para esses problemas, avaliando os resultados do tratamento e melhorando o conhecimento ortodôntico.

Savara, Tracy e Miller (1966), analisaram as medidas tomadas sobre cefalogramas duplicados, realizadas por dois investigadores, e procuraram estabelecer parâmetros entre a distorção radiográfica e a medida real nas medidas tridimensionais de mandíbulas humanas.

Miller, Savara e Singh (1966), em trabalho que analisou os erros de medidas cefalométricas em distâncias tridimensionais na maxila, investigaram uma quantidade de erros inerentes æ̀ medidas cefalométricas, em sete distâncias maxilares, no plano espacial tridimensional. Erros de avaliação, reprodução e precisão foram diferenciados entre si para a validade do estudo e, posteriormente, foram relacionados nas distâncias faciais tridimensionais. Foram feitas dezesseis observações, em cada jogo de cefalogramas. As diferenças encontradas foram significantes, quanto ao plano de tratamento, nos pacientes em crescimento e que se encontravam em situação limite, quanto àindicação ortodôntica, para extração ou não de dentes. 
Carlsson (1967) avaliou os erros e examinou o montante dos efeitos em outros aspectos, tais como: distância foco-filme, técnica de medição, bem como escolha dos pontos e linhas de referências, na precisão das medidas cefalométricas citadas. Este método foi aplicado em estudo longitudinal de esqueletos faciais, em duas séries de pacientes adultos; um grupo com todos os dentes e o outro grupo de pacientes totalmente desdentados.

Concluiu que os erros das medidas foram 5 vezes menores do que os erros na localização dos pontos cefalométicos. Observou, ainda, que as diferenças causadas por erro da técnica radiográfica foram insignificantes. Carlsson observou, também, que as medidas cefalométricas, tomadas a partir de regiões em que a presença de osso alveolar é significativa, por exemplo: ponto A, ponto B e altura maxilomandibular, foram muito alteradas em relação aos padrões cefalométricos nos pacientes desdentados.

Kuam (1969) fez um estudo sobre a diferença entre as medidas cefalométricas, previamente definidas em três pacientes, usando dezoito profissionais para fazer o traçado. Concluiu que a maioria dos erros estava na localização dos pontos cefalométricos.

Baumrind e Frantz (1971) estudaram uma amostra de vinte radiografias, de um total de 122 pacientes tratados na University of California School Dentistry, entre 1954 e 1964. Cinco estudantes do curso de pós-graduação daquela universidade fizeram traçados cefalométricos nas vinte radiografias. Os traçados foram divididos entre erros da tomada radiográfica e erros de traçado, concluindo que:

- o erro na identificação dos pontos cefalométricos é grande demais para ser ignorado;

- a magnitude do erro varia de ponto para ponto; 
- a distribuição do erro pelos pontos cefalométricos é sistemática.

Interlandi (1971) publicou trabalho onde propunha um tipo de

análise para a planificação de tratamento ortodôntico. Empregava-se uma linha de referência cefalométrica baseada em estudo das posições relativas que os incisivos inferiores guardavam com a maxila e a mandíbula. Para tanto propôs a projeção do ponto na linha $P$ que é o plano palatino criando o ponto p'que é a intersecção da linha NA com o plano palatal. A partir deste ponto traçou uma linha que unia o ponto p' ao ponto E (eminência), e então media a distância da incisal do incisivo central inferior a linha I.

Ricketts et al (1972) publicou trabalho onde discute a importância da cefalometria computadorizada na melhora das informações obtidas nas telerradiografias. Observa que as medidas cefalométricas obtidas por meio de analises computadorizadas são mais confiáveis do que as realizadas manualmente, embora seja necessário a estandardização dos pontos craniométricos. Levanta ainda questionamentos sobre as bases científicas com que são feitos os programas de avaliação cefalométrica. Como conclusão entende que o conhecimento clínico das anomalias de desenvolvimento e oclusão são fatores fundamentais para o bom diagnóstico e plano de tratamento.

Gravely e Benzies (1974) escreveram um artigo diferenciando os tipos de erros em cefalometria e classificaram-nos em erros de projeção e erros de traçado. Usaram 103 telerradiografias e submeteram-nas a três profissionais, que fizeram todos os traçados cefalométricos duas vezes, com um intervalo de quarenta dias entre o primeiro e o segundo traçado. Concluíram que houve maior incidência de erro quando o examinador não era ortodontista e que esses erros foram, em sua maioria, feitos na localização dos pontos. 
Bergin, Hallenberg e Malmgren (1978) fizeram estudos com cefalometrias computadorizadas e descobriram que o erro da cefalometria computadorizada é menor do que o dos traçados manuais. Concluíram ainda que os erros, na cefalometria computadorizada, estavam relacionados com a inexperiência do operador na localização dos pontos, pois o erro de transferência dos pontos para o computador variava entre $0 \mathrm{~mm}$ e $0,25 \mathrm{~mm}$, enquanto, manualmente, essa oscilação subia até $3,25 \mathrm{~mm}$.

Houston (1979) escreveu um artigo em que considerava a digitalização das medidas e a sua subseqüente análise como referência para uma série de softwares desenvolvidos pelo autor para esse propósito. Esses softwares foram escritos com linguagem Basic e Fortran, para serem adaptados a uma grande variedade de equipamentos. $\mathrm{O}$ autor discutiu três etapas independentes:

- digitalização e armazenamento dos dados;

- seleção dos dados, de acordo com o interesse do caso;

- análise dos dados.

Broch, Slasgvold e Rosler (1981) estudaram trinta radiografias de crianças entre 9 e 10 anos de idade. Todas as radiografias foram tiradas com o mesmo aparelho e valores idênticos de exposição. Os traçados cefalométricos foram realizados por dois operadores com bastante experiência, pelo método de digitalização. Traçados manuais foram feitos e os erros de localização dos pontos foram reduzidos ou eliminados. Com base nas próprias observações, concluíram que as diferenças de medidas cefalométricas, quando os examinadores eram devidamente calibrados, resumiam-se nas diferenças de localização dos pontos cefalométricos. E que, para o estudo estatístico de um grupo grande, esses erros podiam ser insignificantes; quando, porém, a amostra era pequena ou quando se 
tratava do diagnóstico de determinado paciente, este erro podia ser bastante significativo.

Richardson (1981) estudou cinqüenta radiografias, 25 de homens e 25 de mulheres, de pacientes com doze anos de idade. Aquelas radiografias foram traçadas pelo método de digitalização e manualmente, usando-se quatorze pontos cefalométricos. O estudo demonstrou que a confiabilidade dos valores medidos, na cefalometria com traçado manual, é inferior aos valores medidos na cefalometria digitalizada, porém a diferença não é significante, e que as vantagens do sistema digitalizado são marcantes na obtenção das medidas e na rapidez do resultado.

Stabrum e Danielsen (1982) estudaram a capacidade de reprodutibilidade de 14 pontos cefalométricos, tomados por um mesmo observador e/ou diferentes observadores. Para isso utilizou cem telerradiografias, 50 de meninos e 50 de meninas, com idade média de 12 anos, em que os pontos cefalométricos foram marcados em duas ocasiões diferentes, pelos dois observadores, com intervalo de um mês, usando os pontos Ápex superior, Ápex inferior e primeiros molares. Esses pontos foram depois digitalizados e observou-se que a discrepância entre os dois observadores, embora existisse, era insignificante.

Houston (1982) analisou 25 radiografias, fazendo traçados digitalizados e manuais. E cada radiografia foi traçada duas vezes, em ocasiões diferentes, com espaço de seis meses, para evitar o efeito de memória do operador. Para cada radiografia digitalizada foi repetido o traçado manual imediatamente; as possíveis diferenças não foram relatadas de imediato, para não interferirem na estimativa de erro do profissional.

Concluiu que as diferenças das medidas estavam na localização dos pontos cefalométricos; porém, salientou que se faz necessária uma melhor definição da 
localização exata dos pontos, pois, em algumas regiões, como, por exemplo, a parte anterior da sínfise mentoniana, se esta tiver sua anatomia alterada para uma forma mais plana, haverá grande dificuldade na localização dos pontos pogônio, prémentoniano e ponto eminência.

Houston (1983), após estudos em radiografias, concluiu que a reprodutibilidade dos pontos cefalométricos varia conforme a qualidade das radiografias, as condições e a habilidade do técnico, e que, por esses motivos, muitos estudos deveriam incluir um levantamento da reprodutibilidade dos pontos e medidas usados. Disse, ainda, que esses erros podem ser aleatórios ou sistemáticos. Para ele, os erros sistemáticos normalmente advêm de conceitos equivocados sobre a localização dos pontos cefalométricos. Os erros casuais são provenientes de artefatos de posicionamento dos pacientes durante as tomadas radiográficas ou de distorções nas radiografias. Desta forma, é difícil avaliar a confiabilidade da interpretação, porque não sabemos se a diferença vem da anomalia do paciente, da imprecisão na determinação do ponto cefalométrico ou de problemas relacionados com a técnica radiográfica em si.

McNamara (1984) descreveu um método de análise cefalométrica para avaliação de pacientes a serem tratados com aparelhos ortodônticos ou por meio de cirurgia ortognática. Nesta cefalometria a posição da maxila e da mandíbula foram avaliadas individualmente e em conjunto por meio de uma vertical a Frankfourt partindo do ponto nasio. Com este técnica de análise cefalométrica, o autor pretende avaliar a posição horizontal da maxila e da mandíbula, independente da inclinação da base do crânio. Pretende também mensurar o tamanho efetivo da maxila e mandíbula medindo a distância entre o ponto condílio e o ponto A, para maxila, e a distância entre o ponto condílio e o ponto pogônio para a mandíbula. Concluiu que 
por ser esta análise principalmente baseada em dados lineares, a incidência de erro é menor do que em avaliações feitas a partir de medidas angulares.

Jackson, Dickson e Birnie (1985) realizaram um trabalho comparando medidas cefalométricas obtidas por traçado manual e digitalizado, bem como por meio de imagens digitais, obtidas pelo vídeo, na tela do computador.

Uma parte importante do trabalho deles diz respeito àcaptura de imagens, as quais podem ser feitas de várias formas:

1) Por meio de câmera vídeo/intensificadora, como as usadas em radiografia digital. Este método proporciona imagens dinamizadas; porém, a resolução espacial é limitada;

2) Por meio do uso de scanner, que dá boa resolução espacial, mesmo com pouco contraste;

3) Por meio do uso de uma matriz linear; nela a imagem estática é obtida com bom contraste, mas com resolução espacial limitada;

4) Por meio de scanner microdensitômetro.

A conclusão do trabalho desses autores foi a mesma obtida por Houston (1982), ao afirmar que os métodos computadorizados não apresentavam diferenças estatisticamente significantes, quando feitos a partir de calibração dos pontos cefalométricos, e quando salientavam que as medidas obtidas pelo método computadorizado tinham maior precisão, pois eram feitas por meio de pixels.

Quando usaram o microdensitômetro, obtiveram maior facilidade na localização dos pontos de reparo anatômico.

Sander (1988) estudou três métodos de mensurações angular e linear, manual, digitalização direta e digitalização do traçado, usando 25 radiografias, as quais tinham qualidade suficiente para a identificação dos pontos e não indicavam 
dentes parcialmente erupcionados. Concluiu que os traçados cefalométricos medidos manualmente eram confiáveis; porém, a margem de erro, na técnica de digitalização direta, era menor.

Davis e Mackay (1991) compararam resultados entre traçados manuais e traçados feitos por meio de computadores gráficos interativos. O a melhor resultado foi com cefalometrias em computador gráfico.

Martins et al. (1995) demonstraram, em seu estudo por meio de análises cefalométricas de Steiner, que o erro em cefalometria é constante. E, também, tornou-se evidente a necessidade de contestar as mensurações nas pesquisas científicas, Mostraram, ainda, que o uso do computador não reduziu, significantemente, os erros sistemáticos ou casuais; de modo especial, nas medidas que envolviam os incisivos.

Nimkarm e Miles (1995) fizeram pesquisa para determinar a confiabilidade dos pontos cefalométricos obtidos por meio de cefalometrias digitais, comparados aos traçados manuais. Concluíram que a maioria dos pontos pode ser reproduzida, embora tenha havido diferença na localização do ponto B. Observaram, também, que as medidas obtidas no plano horizontal foram de 0,7 a $1,0 \mathrm{~mm}$ maiores do que as medidas manuais, sendo esta informação útil na interpretação dos dados obtidos por meio de análises cefalométricas computadorizadas.

Rudolph, Sinclair e Coggins (1998) desenvolveram um método de localização automática dos pontos cefalométricos, por meio de método computadorizado chamado SS (Spatial spectroscopy); Concluíram que, as diferenças estatísticas eram menores que 0,05 , quando comparadas ao método manual.

Amad Neto (1998), avaliando 30 telerradiografias de pacientes, entre 8 e 15 anos, que necessitavam de tratamentos ortodônticos, baseados na análise 
cefalométrica de McNamara, comparou as medidas cefalométricas tomadas pelo método manual, por 3 profissionais e por 2 métodos computadorizados, concluindo que houve diferença estatisticamente significante entre os 3 métodos, sendo que a diferença encontrava-se na determinação dos pontos cefalométricos, os quais deveriam ser marcados por profissionais habilitados.

Hagemann et al. (2000) realizaram pesquisa envolvendo 2 ortodontistas, os quais traçaram 21 pontos cefalométricos, 2 vezes cada um, em 100 telerradiografias obtidas pelo método tradicional, e em 100 telerradiografias obtidas por imagem digital. Destacaram que houve coincidência dos pontos cefalométricos intraobservadores, e pouca diferença dos inter-observadores. Ressaltaram também que as medidas lineares e angulares foram mais exatas nas radiografias obtidas pelo método digital, enfatizando que a qualidade das radiografias digitais facilita as medidas cefalométricas.

Um estudo realizado por Y.G. Chen et al. (2000) propôs comparar a definição de pontos cefalométricos, obtidos de radiografias convencionais e digitais. Para isso selecionaram 10 radiografias digitais e convencionais, as quais foram avaliadas por 7 profissionais, que traçaram coordenadas $\mathrm{x}$, e $\mathrm{y}$, para cada ponto cefalométrico, num total de 19 pontos, em cada radiografia convencional e digital.

Observou-se que os pontos que obtiveram diferenças significativas no eixo horizontal foram os Me, Gn, ANS, PNS, LIA, com diferenças acima de $1 \mathrm{~mm}$. Os pontos que mostraram diferenças no eixo vertical, foram os Porio, Orbital e Gnátio. Concluíram, então, que os pontos que obtiveram maior índice de erro em sua determinação foram os Porio, Articulare e A. Por isso, deveriam ter sua localização melhor definida. 
Phelps e Masri (2000), observando a dificuldade de localização do ponto apex no incisivo central inferior, realizaram estudo com 38 crânios, onde foram marcados, com pontos metálicos, os ápices dos incisivos inferiores. Os crânios foram radiografados e o traçado realizado. $\mathrm{Na}$ segunda fase do trabalho, os autores radiografaram apenas as mandíbulas com o ponto apex marcado, posicionando-as no centro do feixe de Rx e, após sobrepor os traçados, concluíram que não houve distorção entre as duas exposições.

Liu, Chen e Cheng (2000) publicaram trabalho a respeito da determinação automática de pontos cefalométricos via computador. Para isso, utilizaram 10 telerradiografias nas quais foram marcados 13 pontos cefalométricos. Os autores dividiram a radiografia em 8 sub-regiões, as quais tiveram suas imagens escaneadas; os pontos foram automaticamente selecionados. A conclusão do trabalho foi que, com exceção dos pontos sella, nasion, poriom, orbital e gnatio, as medidas não puderam ser aceitas como fiéis, quando comparadas àmarcação dos mesmos pontos por via tradicional.

Amad Neto e Chilvarquer (2000) publicaram trabalho avaliando 30 radiografias tomadas para tratamento ortodôntico, tendo suas medidas cefalométricas mensuradas por 3 profissionais especialistas em ortodontia e por 2 métodos de avaliação computadorizada. Concluiu que o ponto $A$ foi o ponto cefalométrico que mostrou maior índice de erro nas medidas cefalométricas independente do método utilizado ser pela técnica manual ou computadorizado.

Held, Ferguson e Gallo (2001), utilizando 13 pontos cefalométricos avaliados em radiografias convencional e digitalizada, com a colaboração de 49 estudantes de ortodontia, avaliaram a acuracia na determinação dos referidos pontos, levando em consideração diversas resoluções de imagem. Variando aos extremos, com relação 
à escala de cinza na radiografia, observaram que a acuracia na determinação dos pontos não teve influência com relação àresolução, a não ser quando os extremos foram utilizados.

Mori et al. (2001), referindo-se ao fato que o método de determinação de pontos cefalométricos utilizava coordenadas tridimensionais, concluíram que esse método, embora pudesse corrigir a magnificação da imagem, não corrigia a máposição do esqueleto cefálico. Em seu estudo, desenvolveram um sistema cefalométrico tri-dimensional, que corrigia não só a magnificação da imagem como também a má-posição tri-dimensional do crânio durante a exposição radiográfica.

Turner e Weerakone (2001) trabalharam comparando 25 radiografias cefalométricas pelos métodos: 1- (Screenceph) que utilizava imagens diretamente do monitor de vídeo com recursos bitmap; 2- Traçado cefalométrico, após determinação digital dos pontos e 3- Digitalização direta dos pontos. A diferença média entre as medidas angulares foi de 0.5 graus e de $0,2 \mathrm{~mm}$ para as medidas lineares, a favor do método "Screenceph", concluindo que este método era bastante confiável para os tratamentos clínicos, mas que não era suficientemente exato quando usado, para projetos de pesquisa, devido às limitações do hardware.

Kamoen, Dermaut e Verbeeck (2001) procederam a uma investigação, cujos objetivos eram determinar os erros que envolviam a identificação de pontos cefalométricos e associar esses erros æ̀ falhas nos resultados dos tratamentos ortodônticos. Cefalogramas de 50 pacientes foram randomizadamente selecionados e avaliados por 4 observadores. Foram observados 35 pontos cefalométricos em cada cefalograma, os quais foram traçados em 10 posições diferentes, em mesas digitalizadoras. Foram selecionados 5 cefalogramas, de cada um dos observadores, para comparação. 
Testes de relevância encontraram não só diferenças entre os observadores, como também encontraram diferenças nas marcações dos pontos, quando realizadas pelo mesmo observador, em ocasiões diferentes. Em conclusão, estimouse um mínimo de interferência destes erros na terapêutica final.

Farkas et al. (2002) estudaram a relação entre pontos cefalométricos e pontos craniométricos, avaliando 25 crânios secos em norma frontal. Seis, dos onze pontos selecionados, foram pontos unitários tomados sobre a linha média no plano orbital, terço médio e face inferior, sendo 2 em cada parte. Dois pontos foram avaliados, um em cada lado da órbita. Os outros 3 foram marcados na face inferior entre o ponto médio do eixo facial e os pontos cefalométricos laterais a esses. As distâncias, tanto para os pontos unitários quanto para os pontos bilaterais, mostraram-se menores que as distâncias craniométricas. As diferenças numéricas foram maiores para os pontos duplos do que para os pontos unitários. Estes autores concluíram que estas diferenças deram-se devido æ̀ falhas de determinação dos pontos usados para a cefalometria, e que estas diferenças não são detectáveis nos tradicionais cefalogramas bi-dimensionais. 


\section{PROPOSIÇÃO}

O objetivo neste estudo é avaliar, de forma quantitativa, as variáveis e as implicações clínicas oriundas da determinação de sete pontos cefalométricos (ponto nasio, ponto espinha nasal anterior, ponto A, ponto pogonio, ponto gnátio, ponto gônio e ponto condílio), em telerradiografias laterais, obtidas por método digital indireto, comparados aos pontos cefalométricos previamente demarcados, com estruturas metálicas (esferas) aplicadas a crânios macerados. 


\section{MATERIAL E MÉTODOS}

\subsection{Material}

Para a presente pesquisa, foram utilizados 14 crânios macerados, cedidos pelo Departamento de Anatomia do Instituo de Ciências Biológicas da USP, com o devido aval do Comitê de Ética da Faculdade de Odontologia da Universidade de São Paulo (ANEXO A).

Os referidos crânios foram radiografados em norma lateral absoluta, utilizando o aparelho Quint Sectograph com regime de trabalho de 58 KVp, 200 mA e 0,3s de exposição, usando Ecrans terras raras e filme Kodak TMATG, 20,3 cm X 25,4 cm, que foram revelados em processadora automática Kodak M35. Posteriormente, as imagens foram escaneadas e digitalizadas em escaner de transparência Hp, utilizando-se o programa Radiocef. ${ }^{\circledR}$ 


\subsection{Método}

Consideramos como pontos craniométricos os pontos marcados sobre os crânios macerados, e pontos cefalométricos os pontos marcados nas telerradiografias.

Nas imagens digitalizadas, foram marcados os seguintes pontos cefalométricos, para futura análise.

Ponto Nasio

Ponto Espinha nasal anterior

Ponto A

Ponto Pogonio

Ponto Gnátio

Ponto Gônio

Ponto Condílio

Após este procedimento, foram marcados nos mesmos crânios, com o auxilio de esferas metálicas adaptadas com silicone gel, os mesmos pontos identificados nas radiografias previamente realizadas.

Os crânios foram, então, novamente radiografados e escaneados. As imagens digitalizadas obtidas foram comparadas às previamente executadas, com a finalidade de testar a reprodutibilidade de identificação dos mesmos pontos cefalométricos.

Os dados coletados foram estatisticamente comparados e analisados pelos métodos de teste "t pareado" e de curva de erro. 


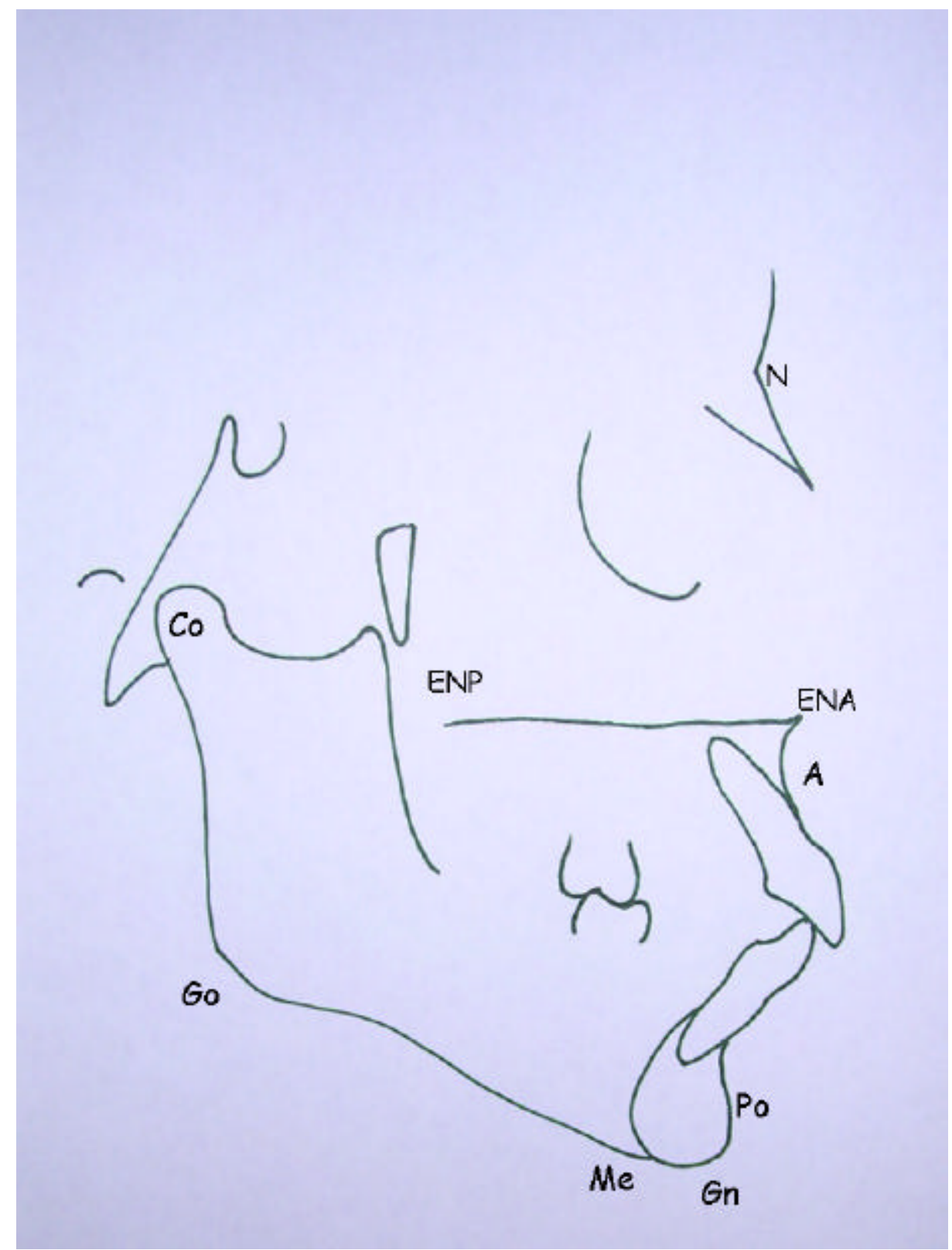

Figura 4.1 - A figura demonstra o traçado cefalométrico com os pontos a serem utilizados na avaliação 
31

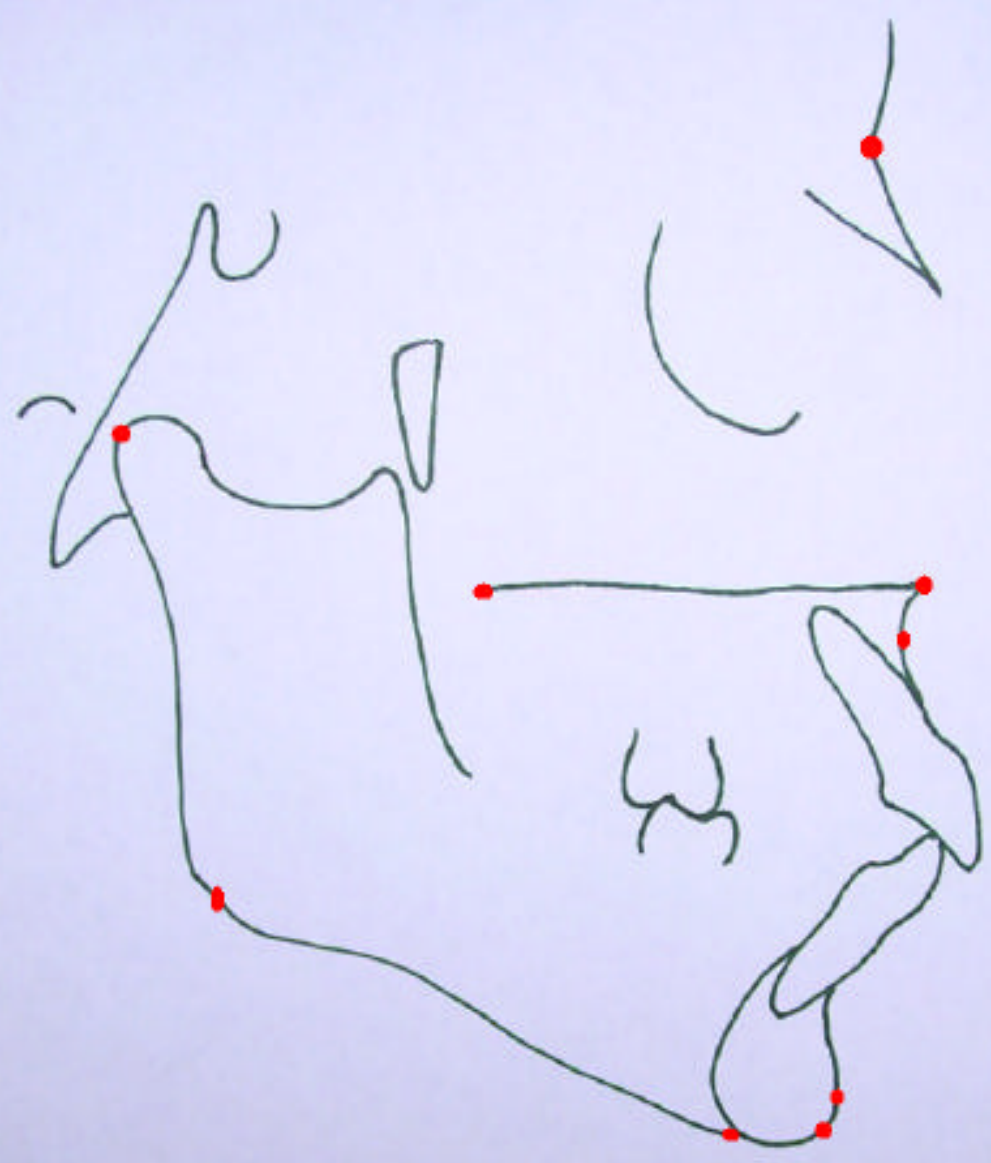

Figura 4.2 - Traçado com os pontos cefalométricos marcados sobre a radiografia do crânio 


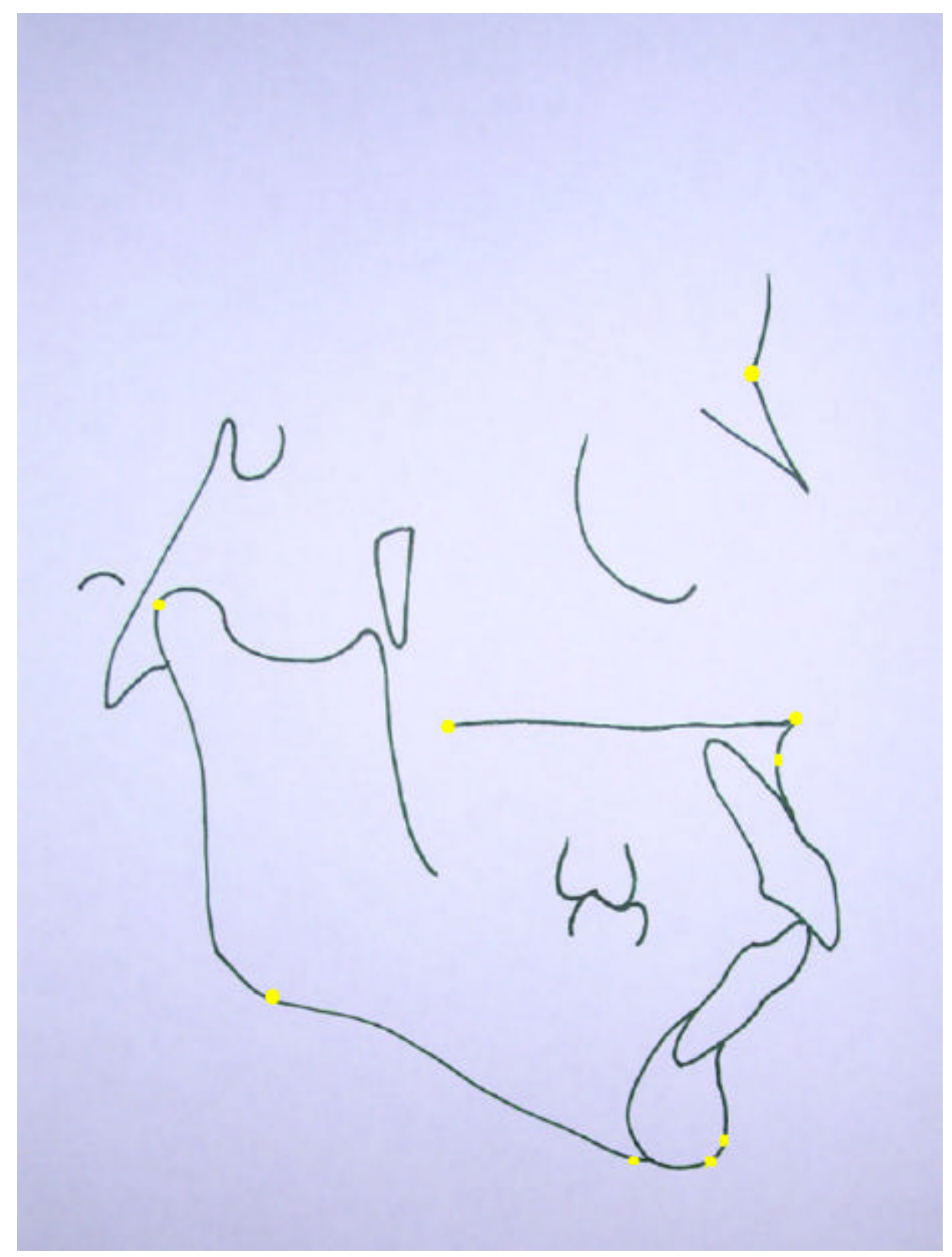

Figura 4.3 - Traçado com os pontos metálicos marcados sobre a radiografia do crânio 


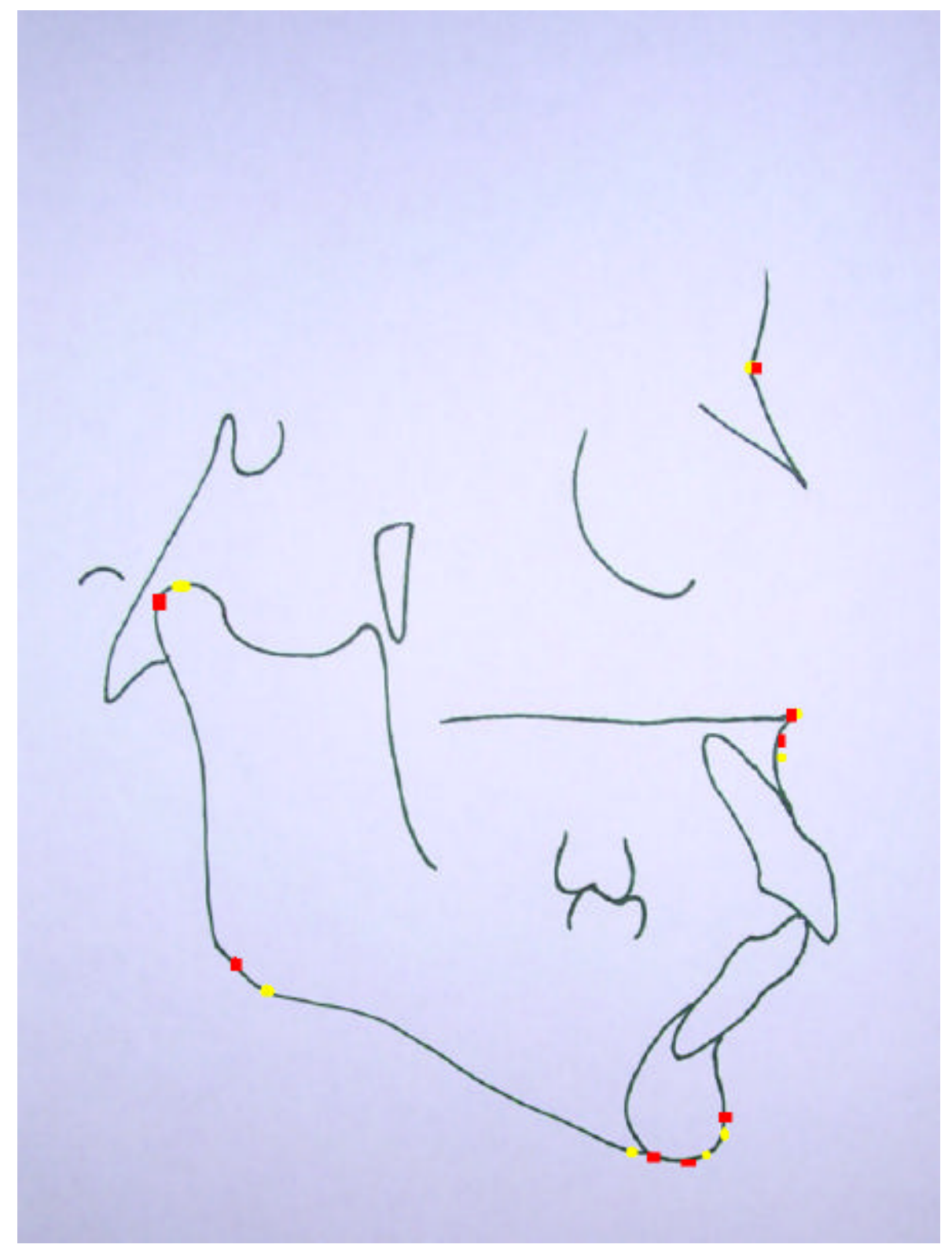

Figura 4.4 - Utilizamos o traçado com sobreposição dos pontos cefalométricos e pontos metálicos, para mensuração das diferenças de localização dos pontos 


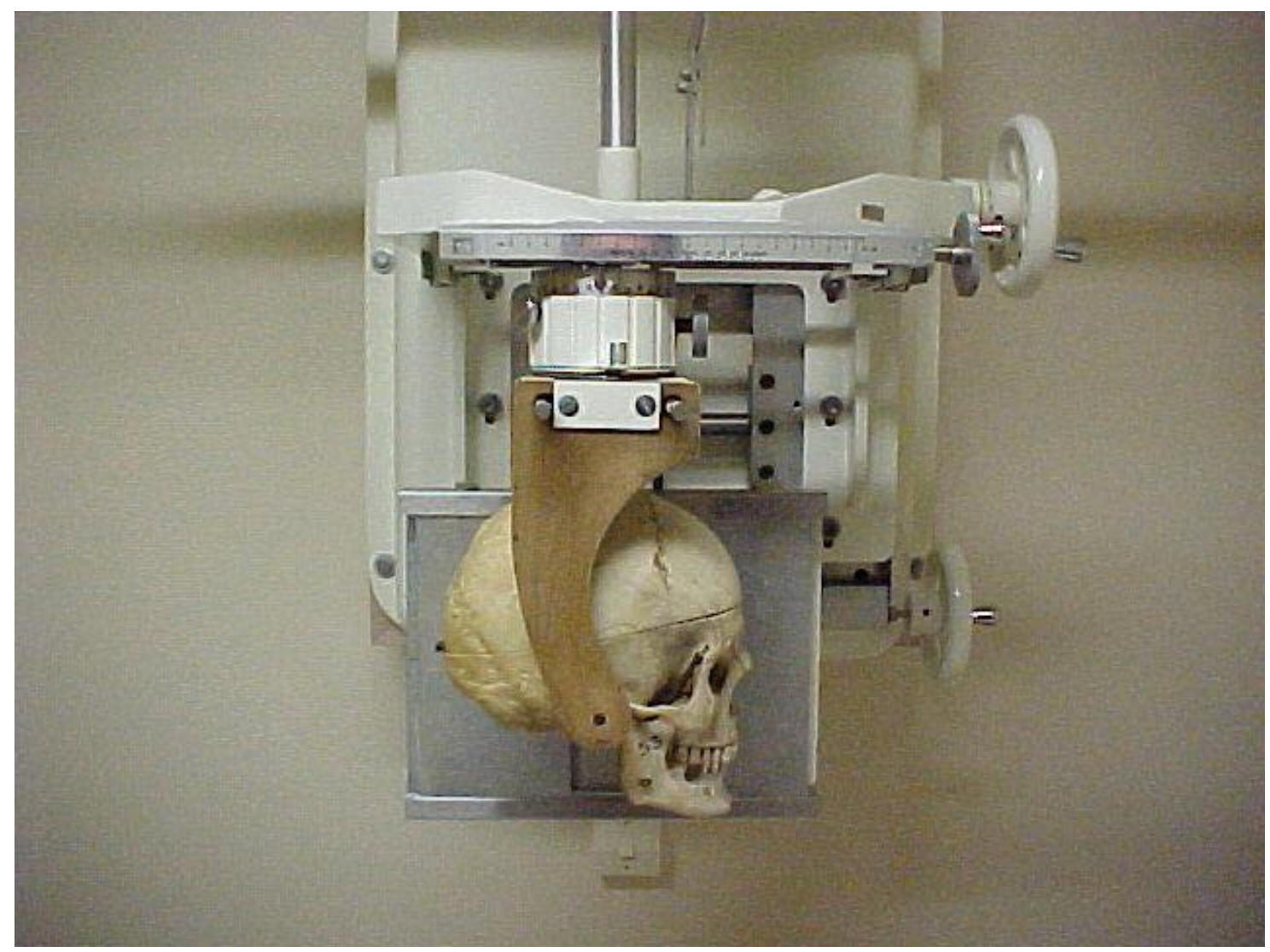

Figura 4.5 - Fotografia do crânio adaptado ao cefalostato no aparelho Quint Sectograph 


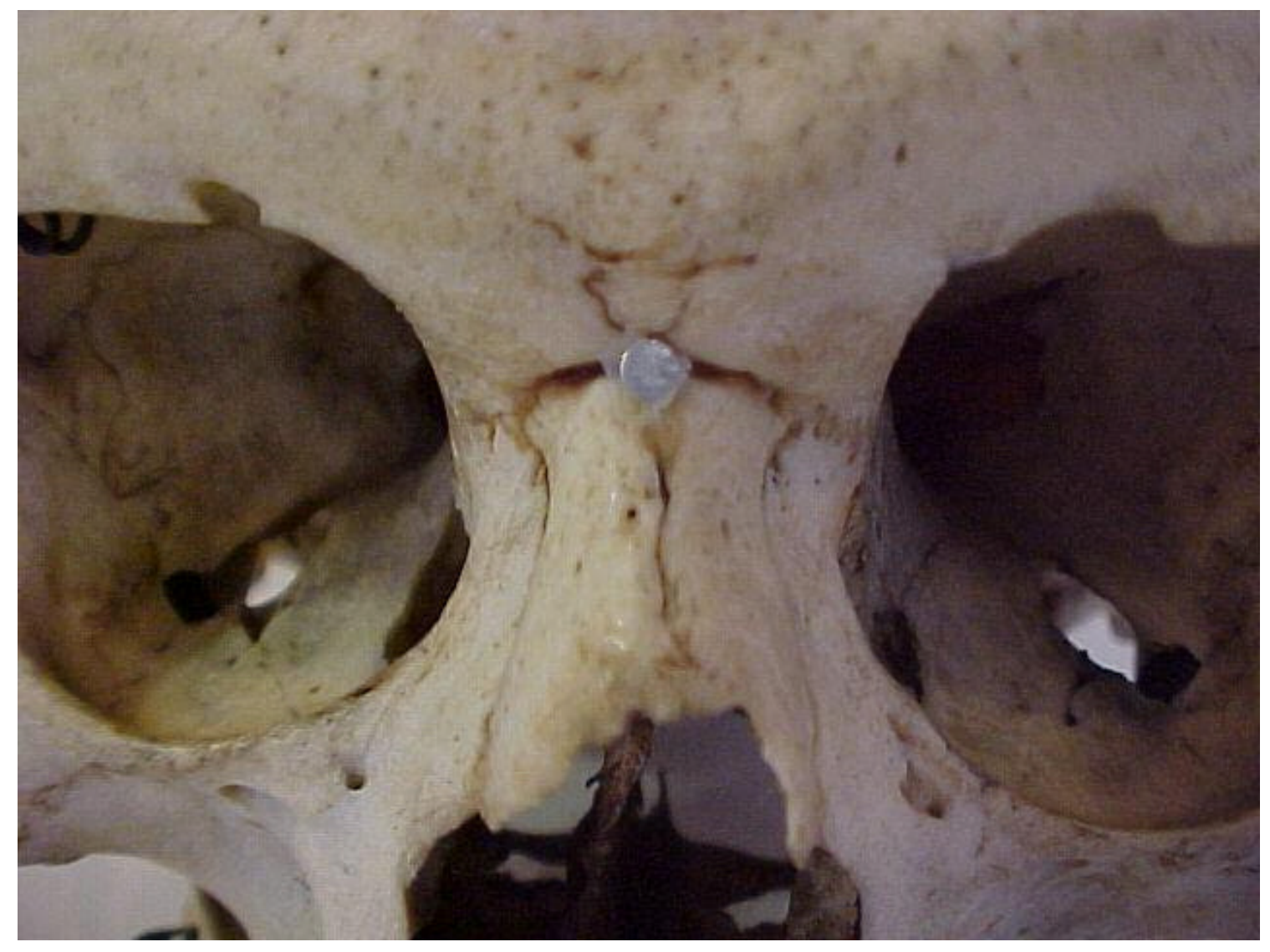

Figura 4.6 - Demonstração da marcação do ponto metálico na região do nasio 


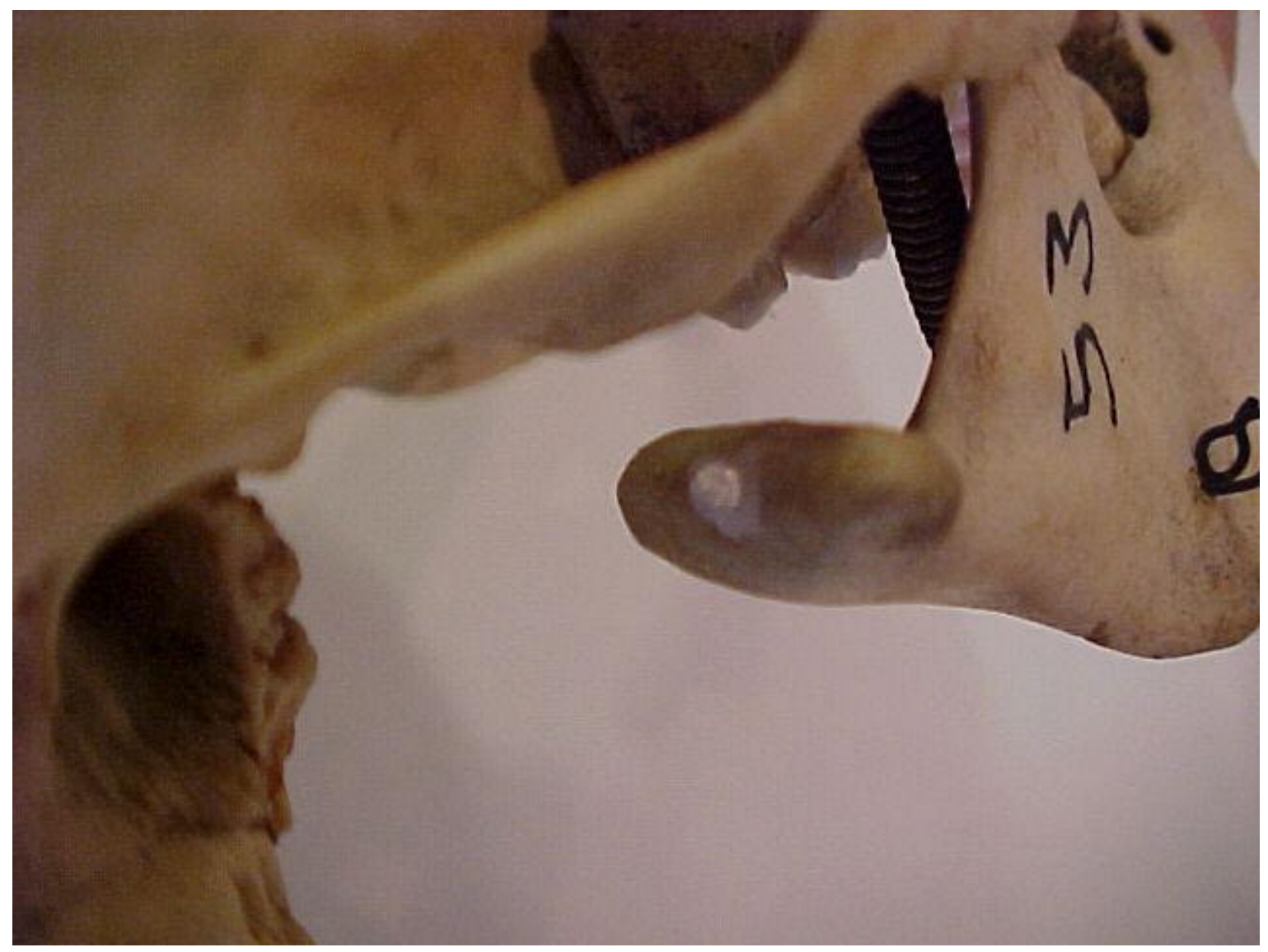

Figura 4.7 - Demonstração da marcação do ponto metálico condílio na região do côndilo 


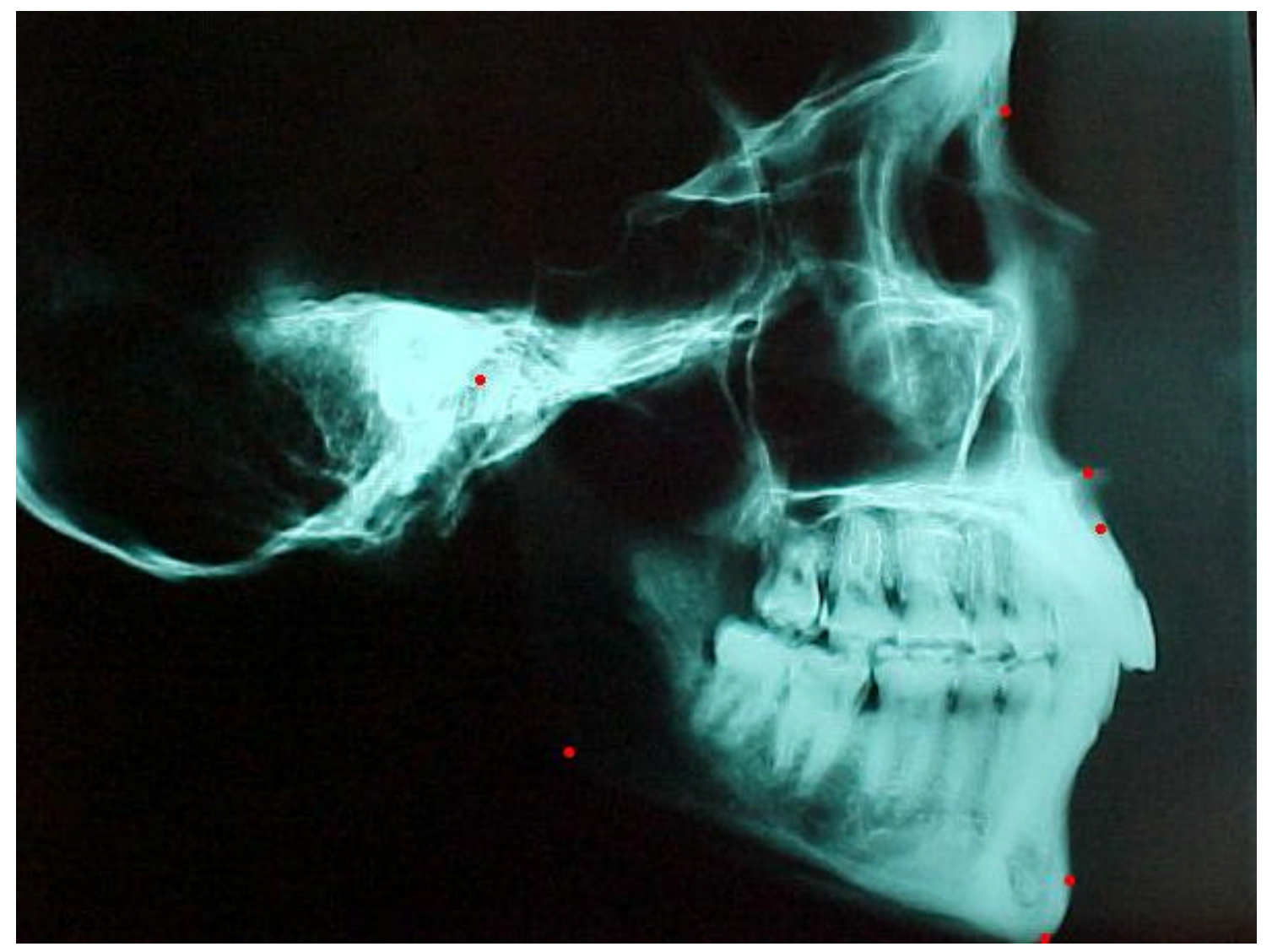

Figura 4.8 - Aspecto da radiografia com os pontos cefalométricos identificados 


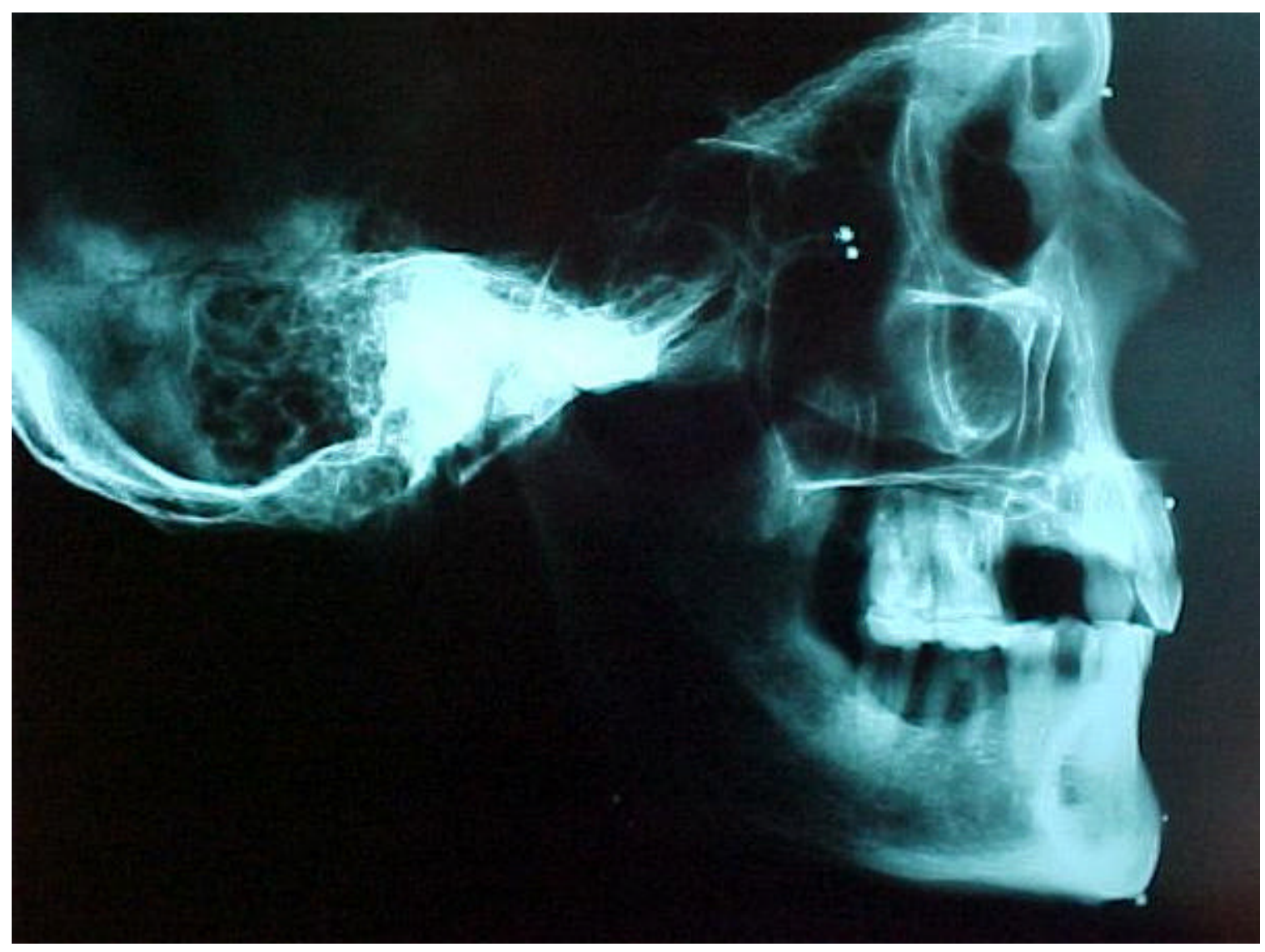

Figura 4.9 - Aspecto da radiografia com os marcadores metálicos nos pontos cefalométricos 


\section{RESULTADOS}

O objetivo neste estudo estatístico é calcular um tamanho de amostra que nos permita tomar uma decisão sobre a veracidade ou não da seguinte hipótese/afirmação: a diferença entre as medidas de um determinado traçado do crânio, medidas estas obtidas pelos métodos padrão (normal) e por meio de avaliação (marcado), é, com grande probabilidade $\left(P_{\text {total }}\right)$, menor do que um determinado valor pré-estabelecido. Este valor deve ser determinado pelo profissional, considerando o erro máximo que ele pode admitir para a boa realização de seu trabalho.

Tendo em vista o objetivo acima, desenvolvemos um método para o cálculo do tamanho da amostra. Para tanto, foi necessário considerar algumas hipóteses. As hipóteses assumidas, por sua vez, também devem ser possíveis de serem avaliadas com o tamanho calculado de amostra.

A primeira etapa deste estudo foi determinar a margem de erro admitido, ou seja, o desvio padrão, para a análise estatística.

Utilizamos uma amostra piloto para fornecer o desvio padrão, o qual produziu um valor igual a 2,31 mm (Tabela 5.1). 
Tabela 5.1 - Resultados fornecidos pela amostra piloto

\begin{tabular}{c|c|c}
\hline $\begin{array}{c}\text { método padrão } \\
\text { (Normal) }\end{array}$ & $\begin{array}{c}\text { método em } \\
\text { avaliação } \\
\text { (Marcado) }\end{array}$ & diferença \\
\hline 9 & 11 & 2,0 \\
\hline 7,5 & 9 & 1,5 \\
\hline 94 & 96 & 2,0 \\
\hline 121 & 119 & $-2,0$ \\
\hline 72 & 73 & 1,0 \\
\hline 126 & 122 & $-4,0$ \\
\hline 58 & 59 & 1,0 \\
\hline \multicolumn{2}{r}{ desvio padrão = média = } & $\mathbf{0 , 2}$ \\
$\mathbf{2}$ & $\mathbf{2 , 3 1}$ \\
\hline \multicolumn{2}{r}{}
\end{tabular}

A segunda etapa da análise estatística teve o objetivo de determinar o tamanho necessário da amostra necessária para testar as hipóteses assumidas.

Tabela 5.2 - possíveis valores para $n 1$

\begin{tabular}{cccc}
\hline $\boldsymbol{\alpha}_{1}$ & $\boldsymbol{\alpha}_{2}$ & $\mathbf{E}$ & $\mathbf{n}$ \\
\hline $5 \%$ & $5 \%$ & 4,8 & $\mathbf{9 8}$ \\
& & 5,0 & $\mathbf{5 9}$ \\
& & 5,5 & $\mathbf{3 1}$ \\
\hline $10 \%$ & $5 \%$ & 4,0 & $\mathbf{1 0 5}$ \\
& & 4,5 & $\mathbf{3 5}$ \\
& & 5,0 & $\mathbf{2 2}$ \\
\hline $5 \%$ & $10 \%$ & 4,8 & $\mathbf{7 3}$ \\
& & 5,0 & $\mathbf{4 4}$ \\
& & 5,5 & $\mathbf{2 3}$ \\
\hline $10 \%$ & $10 \%$ & 4,0 & $\mathbf{7 8}$ \\
& & 4,5 & $\mathbf{2 6}$ \\
& & 5,0 & $\mathbf{1 7}$ \\
\hline
\end{tabular}


Tabela 5.3 - Possíveis valores para $\mathrm{n}_{2}$, assumindo $\sigma=2,31$

\begin{tabular}{ccccc}
\hline & & & $\boldsymbol{\alpha}_{3}$ & \\
& & $\mathbf{1 \%}$ & $\mathbf{5 \%}$ & $\mathbf{1 0 \%}$ \\
\hline \multirow{\varepsilon}{*}{} & $\mathbf{0 , 5}$ & 142 & 82 & 57 \\
& $\mathbf{0 , 7}$ & 72 & 42 & 29 \\
& $\mathbf{1 , 0}$ & 36 & 20 & 14 \\
\hline
\end{tabular}

- $\quad \mathrm{N}=142$ é um valor que permite detectar erros de até 4,8 $\mathrm{mm}$ nas diferenças das medidas ou $0,5 \mathrm{~mm}$ na média, com probabilidade total de $89,3 \%$;

- $\quad \mathrm{N}=98$ é um valor que permite detectar erros de até $4,8 \mathrm{~mm}$ nas diferenças das medidas ou $0,5 \mathrm{~mm}$ na média, com probabilidade total de $85,7 \%$;

- $\quad \mathrm{N}=73$ é um valor que permite detectar erros de até $4,8 \mathrm{~mm}$ nas diferenças das medidas ou $0,7 \mathrm{~mm}$ na média, com probabilidade total de $84,6 \%$.

Em termos de magnitude, $\mathrm{N}=150$ é um valor adequado para garantir decisões com alto grau de exigência. No entanto, caso este seja um tamanho de amostra difícil de ser obtido na prática, tendo em vista as dificuldades inerentes ao estudo, sugerimos $\mathrm{N}=100$. Valores abaixo de 70 não permitem decisões confiáveis.

De acordo com a curva de erro obtida, podemos concluir, por exemplo, que: com probabilidade de $77,9 \%$, o método erra $1 \mathrm{~mm}$ ou mais; com probabilidade de $57,5 \%$, o método erra $2 \mathrm{~mm}$ ou mais; ou ainda, com probabilidade de $26,7 \%$, o método erra $4 \mathrm{~mm}$ ou mais (Ver Tabela 5.2).

Esta análise indica que o método de medição não parece ser adequado, uma vez que apresentou uma elevada probabilidade de cometer um erro maior do que aquele aceitável na prática. 


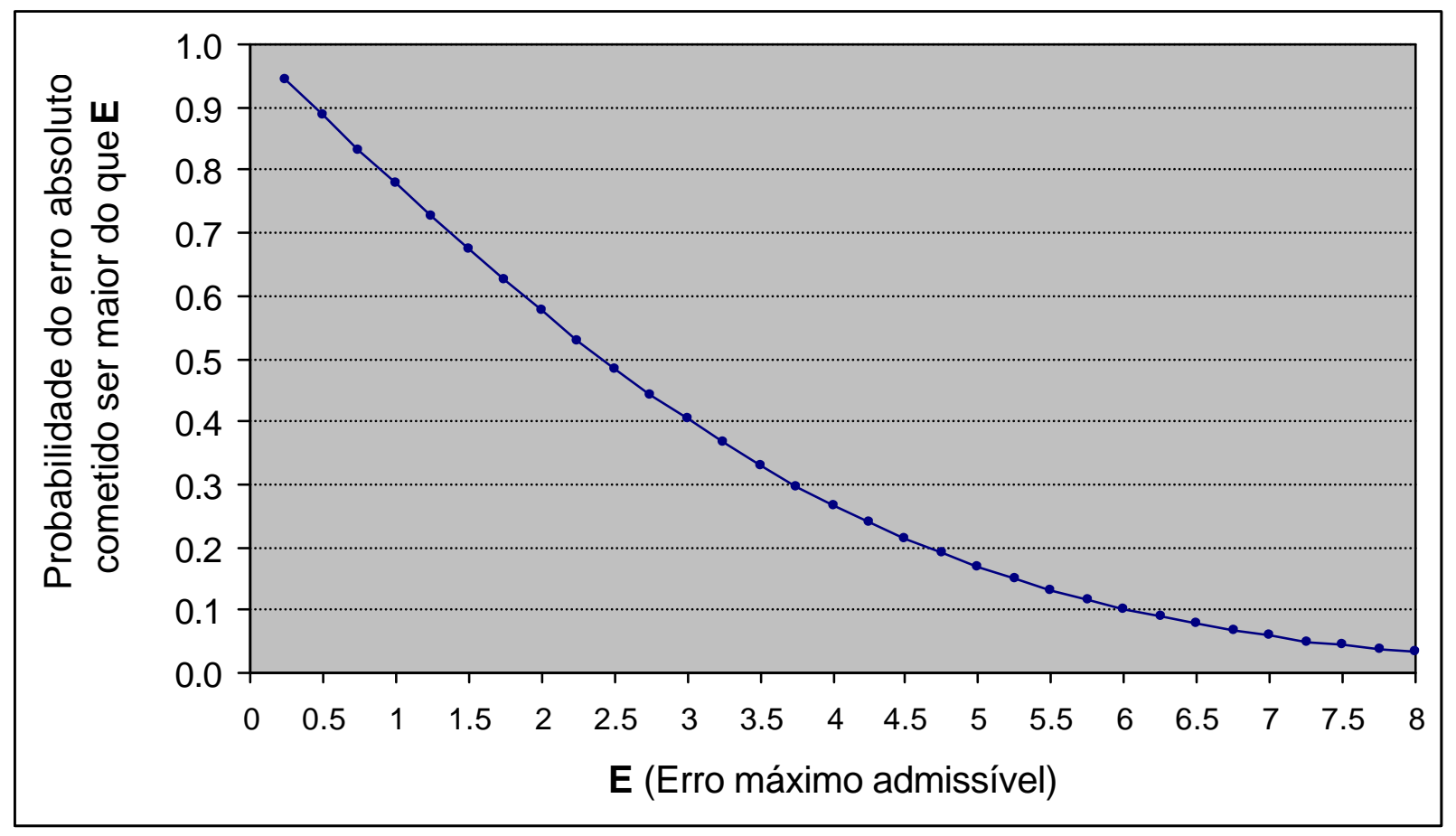

Figura 5.10 - Curva de avaliação do método 
Tabela 5.4 - Valores das probabilidades do erro absoluto cometido, utilizando o método em avaliação, ser maior do que o erro máximo admissível

\begin{tabular}{|c|c|}
\hline $\begin{array}{c}\mathbf{E}(\text { em } \mathrm{mm}) \\
\text { (erro máximo } \\
\text { admissível) }\end{array}$ & Probabilidade \\
\hline 0,25 & 0,9440 \\
\hline 0,50 & 0,8883 \\
\hline 0,75 & 0,8331 \\
\hline 1,00 & 0,7789 \\
\hline 1,25 & 0,7257 \\
\hline 1,50 & 0,6739 \\
\hline 1,75 & 0,6238 \\
\hline 2,00 & 0,5754 \\
\hline 2,25 & 0,5289 \\
\hline 2,50 & 0,4846 \\
\hline 2,75 & 0,4425 \\
\hline 3,00 & 0,4027 \\
\hline 3,25 & 0,3652 \\
\hline 3,50 & 0,3302 \\
\hline 3,75 & 0,2975 \\
\hline 4,00 & 0,2672 \\
\hline 4,25 & 0,2392 \\
\hline 4,50 & 0,2134 \\
\hline 4,75 & 0,1899 \\
\hline 5,00 & 0,1684 \\
\hline 5,25 & 0,1489 \\
\hline 5,50 & 0,1313 \\
\hline 5,75 & 0,1154 \\
\hline 6,00 & 0,1012 \\
\hline 6,25 & 0,0884 \\
\hline 6,50 & 0,0771 \\
\hline 6,75 & 0,0670 \\
\hline 7,00 & 0,0581 \\
\hline 7,25 & 0,0503 \\
\hline 7,50 & 0,0434 \\
\hline 7,75 & 0,0374 \\
\hline 8,00 & 0,0321 \\
\hline
\end{tabular}

Os dados obtidos demonstram que não podemos admitir erros maiores que $2 \mathrm{~mm}$, pois isso implicaria em alteração de medida de até $4 \mathrm{~mm}$, em função de o desvio poder ser tanto para um lado como para outro, em relação àdeterminação do ponto cefalométrico. 


\section{DISCUSSÃO}

O cefalograma lateral do crânio é o método mais utilizado para que, por meio de uma imagem bidimensional de uma estrutura tridimensional, avaliemos a morfologia da face e dos dentes, bem como identifiquemos os desvios de padrões de crescimento estabelecidos como normais e suas conseqüentes alterações, decorrentes do crescimento, do tratamento ortodôntico e das cirurgias ortognáticas.

A análise cefalométrica, que visa identificar pontos cefalométricos de referência anatômica, para que possa ser utilizada para mensurar as posições espaciais tanto de ossos quanto de dentes, deverá ser de livre escolha do profissional, baseando-se na experiência diagnóstica dele e podendo ser influenciada pela técnica selecionada para tratamento (BRODIE, 1954).

A correta localização dos pontos anatômicos depende, antes de tudo, do conhecimento da anatomia radiográfica, como foi estimado por Baumrind e Frantz (1971) quando avaliaram 122 radiografias de pacientes, as quais tiveram o traçado cefalométrico determinados por estudantes do curso de pós-graduação, onde ficou claro que o conhecimento da anatomia crânio facial foi um fator determinante na correta localização dos pontos cefalométricos.

O traçado cefalométrico é um recurso terapêutico definido como exame complementar, portanto deve ser tratado com tal, pois, as variáveis observadas 
durante o exame e o traçado cefalométrico, mostram uma grande quantidade de equívocos.

As variáveis vão desde o posicionamento do paciente, até o conhecimento das estruturas anatômicas envolvidas na análise, pois, a reprodutibilidade é um fator crítico na análise (MORI et al. 2001).

É necessária uma radiografia de boa qualidade, para que a determinação dos pontos cefalométricos seja feita com a maior precisão possível, uma vez que existem distorções radiográficas inerentes ao processo laboratorial e à própria conformação morfológica das estruturas ósseas faciais.

Estas distorções foram estudadas por Mortimar, Levine e Rowe ${ }^{4}$ (19 apud de Adams, 1940). Determinaram que existia um aumento de 4 a $6 \%$ nas estruturas crânio cefálicas e que esta distorção devia ser adotada em escala corretiva para todo o conjunto de medidas e não para cada ponto individualmente.

Preocupados com os erros na determinação dos pontos cefalométricos, autores como Adams (1940), Downs (1948) e Riedel (1957) identificaram que uma grande margem de erro era advinda de problemas na calibração dos aparelhos de RX utilizados e do incorreto posicionamento do paciente quando da execução das telerradiografias.

Amad Neto (1998), Amad Neto e Chilvarquer (2000), Baumrind (1971), Gravely e Benzies (1974), Holdaway (1956), Kuan (1969), Riedel (1957), Steiner (1959) demonstraram, em seus estudos, que as diferenças no diagnóstico ortodôntico eram provenientes de diferenças nas medidas cefalométricas obtidas, quando uma mesma radiografia era traçada e analisada por diversos profissionais.

\footnotetext{
${ }^{4}$ Mortmar
} 
Com o advento dos métodos computadorizados, passamos a observar uma diminuição das diferenças de medidas cefalométricas, uma vez que a precisão das referidas medidas tornou-se significativamente mais acurada pelas características intrínsecas da mensuração por pixels do computador.(DAVIS; MACKAY, 1991; HOUSTON, 1979; RICHARDSON, 1981; SANDER, 1988).

Neste trabalho experimental, procuramos testar a validade e a precisão na determinação dos pontos cefalométricos usados, para determinação do diagnóstico e do tratamento dos pacientes que se submeteram a tratamento ortodôntico.

Radiografias foram realizadas em crânios macerados e, após os cefalogramas serem executados, os pontos anatômicos correspondentes foram marcados com esferas metálicas de $1 \mathrm{~mm}$ de diâmetro e novamente radiografados e seus cefalogramas refeitos.

A definição de pontos craniométricos, como sendo os pontos anatômicos observados diretamente nos crânios macerados, e pontos cefalométricos os mesmos pontos observados nas telerradiografias (SICHER; DUBRUL, 1991).

Os resultados obtidos puderam ser facilmente analisados, devido ao fato de que a perfeita padronização da técnica radiográfica e o correto posicionamento do crânio no cefalostato foram possíveis pela orientação espacial com o plano de Frankfourt, estando sempre paralelo ao solo. Todo este processo de normatização da técnica radiográfica foi feito por Amad Neto (1998), quando avaliou os resultados obtidos por comparação de diferentes técnicas de medição cefalométrica, computadorizada e manual. Concluiu que os erros de posicionamento corroborados por Carlsson (1967), são um fator de erro nas mensurações cefalométricas (RUDOLPH; SINCLAIR; COGGINS, 1998). 
Em seu trabalho, Amad Neto e Chilvarquer (2000), comparam diversas radiografias obtidas em diversos aparelhos e concluiu que a resolução de imagem e o contraste são significantes, em termos estatísticos, para a boa identificação dos pontos cefalométricos.

Mesmo tomando o cuidado de colocar os pontos metálicos, identificando anatomicamente os pontos cefalométricos, apesar do correto posicionamento do crânio no cefalostato e tendo-se observado todos os parâmetros de posicionamento e de qualidade radiográfica, houve uma significante diferença entre as medidas feitas na radiografia com os pontos cefalométricos marcados e as radiografias sem a marcação prévia dos pontos analisados.

Tabela 6.1 - Tabela de medidas utilizada no projeto piloto

\begin{tabular}{l|c|c}
\hline & Normal & \multicolumn{1}{l}{ Marcado } \\
\hline Distancia A - Na perp. & $9,1 \mathrm{~mm}$ & $1,3 \mathrm{~mm}$ \\
\hline Distancia Pg - Na perp & $7,5 \mathrm{~mm}$ & $9,4 \mathrm{~mm}$ \\
\hline Distancia Co -- A & $94,4 \mathrm{~mm}$ & $96,5 \mathrm{~mm}$ \\
\hline Distancia Co -- Gn & $121,3 \mathrm{~mm}$ & $119,2 \mathrm{~mm}$ \\
\hline Distancia ENA -- Me & $72,3 \mathrm{~mm}$ & $73,2 \mathrm{~mm}$ \\
\hline Distancia Na - Gn & $126,0 \mathrm{~mm}$ & $122,1 \mathrm{~mm}$ \\
\hline Distancia Na -- ENA & $58,2 \mathrm{~mm}$ & $59,0 \mathrm{~mm}$ \\
\hline
\end{tabular}

Após a análise da estatística, observamos que o erro nas medidas, que são provenientes do erro na localização dos pontos cefalométricos leva à alteração da medida que muda, significantemente, o diagnóstico e o planejamento do tratamento ortodôntico (AMAD NETO 1998; AMAD NETO; CHILVARQUER, 2000; BROCH; SLAGSVOLD; ROSLER, 1981). 
Determinadas medidas incorrem a erros mais importantes, dependendo do tipo de cefalograma a ser utilizado pelo profissional e do tipo de má-oclusão do paciente (MILLER; SAVARA; SINGH, 1966).

Pontos que estão colocados em estruturas planas são mais bem definidos do que pontos em estruturas curvas ou arredondadas (HELD; FERGUSON; GALLO, 2001; HOUSTON, 1982; JACKSON; DICKSON; BIRNIE, 1985).

Tomaremos como base de estudo a localização do ponto Condílio e do ponto A, pois foram estes os pontos que apresentaram maiores alterações de localização. Estudaremos, também, o ENA, que foi o ponto com menor alteração.

O ponto Condilio, segundo seu método de localização, descrito como sendo o ponto mais póstero-superior do côndilo da mandíbula, não se mostra confiável para a determinação do comprimento mandibular, segundo McNamara (McNAMARA, 1984). Portanto, a medida condílio gnátio nas telerradiografias não representa a maior distância da mandíbula; diante disso, anatomicamente, a união distal e a união mesial da cabeça do côndilo encontram-se mais superior anterior do que mais superior posterior do côndilo (MILLER; SAVARA; SINGH, 1966).

Outra dificuldade com relação ao ponto condílio é que a localização radiográfica dele depende da capacidade de se identificar o contorno do côndilo, porque o mesmo, sendo uma estrutura dupla, sobrepõe-se e dificulta a identificação (FARKAS, 2002; LIU; CHEN; CHENG, 2000). 
Tabela 6.2 - Demonstração das medidas entre o ponto condílio e ponto A, em radiografias com pontos cefalométricos e pontos marcados

\begin{tabular}{c|c|c}
\hline & Rx marcado & Rx não marcado \\
\hline$R x \# 42$ & 100,1 & 97,0 \\
\hline$R x \# 49$ & 93,3 & 96,7 \\
\hline$R x \# 53$ & 87,0 & 84,2 \\
\hline$R x \# 58$ & 100,5 & 98,4 \\
\hline$R x \# 96$ & 95,5 & 93,3 \\
\hline$R x \# 963$ & 92,6 & 92,3 \\
\hline$R x \# 101$ & 96,3 & 97,6 \\
\hline$R x \# 107$ & 92,6 & 93,7 \\
\hline$R x \# 127$ & 102,1 & 99,4 \\
\hline$R x \# 136$ & 97,7 & 95,5 \\
\hline$R x \# 137$ & 96,0 & 96,1 \\
\hline$R x \# 153$ & 82,1 & 85,9 \\
\hline$R x \# 158$ & 82,4 & 81,2 \\
\hline$R x \# 187$ & 101,2 & 103,0 \\
\hline
\end{tabular}

Outro ponto que apresenta muita dificuldade de localização confiável é o ponto $\mathrm{A}$, porquanto a localização radiográfica dele é bastante diferente de sua localização anatômica. O ponto $A$, que é definido como o ponto mais profundo do contorno anterior da maxila, pela sobreposição do processo alveolar, pela inclinação da raiz do incisivo central superior e pela sobreposição da imagem dos tecidos moles sobre o osso maxilar, leva à alteração de localização deste ponto, o qual é muito utilizado nas mensurações cefalométricas (CARLSSON, 1967).

Tabela 6.3 - Demonstração das medidas entre o ponto A e a linha nasio perpendicular, em radiografias com pontos cefalométricos e pontos marcados

\begin{tabular}{c|c|c}
\hline & $\begin{array}{c}\mathrm{Rx} \\
\text { marcado }\end{array}$ & $\mathrm{Rx}$ não marcado \\
\hline$R x \# 42$ & 7,3 & 4,2 \\
\hline$R x \# 49$ & 9,0 & 9,2 \\
\hline$R x \# 53$ & $-2,2$ & $-3,0$ \\
\hline$R x \# 58$ & 12,4 & 10,6 \\
\hline$R x \# 96$ & 2,1 & 1,4 \\
\hline$R x \# 963$ & 0,2 & 3,2 \\
\hline$R x \# 101$ & 3,7 & 0,8 \\
\hline$R x \# 107$ & 7,3 & 6,4 \\
\hline$R x \# 127$ & 6,8 & 4,5 \\
\hline$R x \# 136$ & 3,5 & 0,0 \\
\hline$R x \# 137$ & 3,1 & 3,3 \\
\hline$R x \# 153$ & 5,7 & 4,5 \\
\hline$R x \# 158$ & 6,3 & 4,5 \\
\hline$R x \# 187$ & 4,9 & 5,8 \\
\hline
\end{tabular}


Interlandi (1971) propôs modificação da avaliação do ponto A, projetando o ponto A no plano palatal, com o intuito de evitar que a mecânica ortodôntica, que altera a posição da raiz dos incisivos centrais superiores, e conseqüentemente, a formação óssea anterior, transforme a posição do ponto A.

Esta alteração do osso alveolar, que modifica a posição do ponto $A$, mostra que a utilização do ponto $A$ como parâmetro de localização da maxila com relação à base do crânio, ângulo SNA (STEINER, 1959), não é confiável antes do tratamento ortodôntico, pela dificuldade de localização do ponto $A$ e, também, não é confiável como avaliação do tratamento ortodôntico, visto que este ponto pode ser alterado com a mecânica ortodôntica (MARTINS, 1995).

A tentativa feita por Interlandi, projetando o ponto A no plano palatal, também, não nos parece adequada, porque iremos projetar o ponto $\mathrm{A}$ que, de antemão, não foi bem definido e que, também, não representa a real posição da maxila com a base do crânio.

Observamos, ainda, que a diferença média na localização dos pontos cefalométricos tem $57,5 \%$ de chance de alteração de mais de $2 \mathrm{~mm}$ de diferença, sendo que a diferença para o ponto $\mathrm{A}$ é de $68,5 \%$. Dados semelhantes na magnitude de erro foram obtidos por Bergin, Hallenberg e Malmgrem (1978), quando observaram diferenças de até $3,25 \mathrm{~mm}$ na localização do referido ponto cefalométrico.

Quando ponderamos que uma medida cefalométrica leva em consideração pelo menos 2 pontos craniométricos e que a diferença de cada ponto tem uma chance muito grande da discrepância ser, pelo menos, $2 \mathrm{~mm}$ em cada ponto, e a somatória deste erro pode levar à alteração de aproximadamente até $4 \mathrm{~mm}$, já que 
estabelecemos um desvio padrão máximo que não poderá ser maior que 2,31mm, segundo dados obtidos da análise estatística (Tabela 5.1).

Na terapêutica ortodôntica, cujo objetivo é obter uma oclusão adequada e precisa, devendo levar em consideração que a distância entre os incisivos centrais superiores e inferiores no sentido antero-posterior, distância esta definida como sobressaliência ou overjet, esperando-se tentar finalizar o tratamento ortodôntico com um overjet de $2,5 \mathrm{~mm}$ ao máximo de $3 \mathrm{~mm}$ (Ricketts, 1970), uma alteração na mensuração de $4 \mathrm{~mm}$, poderia levar ao término do tratamento com uma sobressaliência significantemente maior com uma variação de $5 \mathrm{~mm}$ ou até $7 \mathrm{~mm}$. Portanto nos parece de suma importância a correta localização radiográficas dos incisivos, principalmente o ápice dos incisivos utilizados na mensuração da angulação dos incisivos ( STABRUN; DANIELSEN, 1982; PHELPS; MASRI, 2000).

Esta avaliação clinica é corroborada pelos estudos de Kamoen, Dermaut e Verbeeck (2001) que por meio de comparações de traçados cefalométricos sobrepostos conseguiu observar que diferenças na localização do ponto $A$ e do ponto B alteraram, significantemente, a avaliação da posição da maxila e da mandíbula em relação à base do crânio, quando foram feitas em radiografias de pacientes, realizadas antes e após o tratamento ortodôntico, e comparadas com o resultado clínico, concluindo que as alterações na localização de pontos cefalométricos podem levar a equívocos de diagnóstico importantes com conseqüências no resultado do tratamento (NIMKARM, MILES; 1995).

Quando se tenta normatizar a localização radiográfica de pontos craniométricos, observa-se grande dificuldade em definir a localização do ponto. Inicialmente pela variação anatômica das estruturas ósseas e, segundo, pela incapacidade de relacionar o ponto indicado e localizado, com a real posição 
espacial da estrutura anatômica que se pretende avaliar (AMAD NETO, 1998; AMAD NETO; CHILVARQUER, 2000).

Parece-nos que o melhor caminho para melhorar o diagnóstico cefalométrico será o de redefinir os pontos usados na identificação de certas estruturas ou criar novos pontos craniométricos, cujas localizações sejam mais exeqüíveis, precisas e que demonstrem dados reais e compatíveis com a localização e o tamanho da estrutura anatômica que se quer avaliar.

$\mathrm{Na}$ avaliação da posição da maxila, no sentido vertical, contamos com a medida Na-Cf-A de Rickets (RICKETTS, 1970), que, por meio de um dado angular, tentou definir a posição da maxila no plano vertical. Sabemos que medidas angulares, que levam em consideração 3 pontos, aumentam, significantemente, a margem de desvio das grandezas cefalométricas, as quais podem estar alteradas, inclusive, pela inclinação do plano palatal (BAUMRIND; FRANTZ 1971; HAGEMANN et al., 2000; HOUSTON, 1983; TURNER; WEERAKONE, 2001).

Esta medida leva em consideração, apenas, a posição vertical da parte anterior da maxila e não a posição total da maxila.

Sugerimos que a mensuração para avaliação da maxila no sentido vertical seja feita pela avaliação de uma medida linear entre o ponto nasio que se mostrou bastante confiável, e o ponto ENA que, também, apresentou pouca variação entre o ponto craniométrico que foi identificado com o marcador metálico de nosso material e método, e o ponto cefalométrico, cujas localizações são apresentadas pelos seguintes autores, (AMAD NETO 1998; AMAD NETO; CHILVARQUER, 2000; CHEN et al., 2000; McNAMARA, 1984; STEINER, 1959). 
As medidas preliminares mostram que a variação entre a medida craniométrica e a medida cefalométrica foi pequena, e que estes desvios nas mensurações não se apresenta estatisticamente significante.

As medidas de avaliação do plano palatal em relação ao plano de Frankfourt (RICKETTS et al., 1972) mostram a possibilidade de medirmos a quantidade de inclinação do plano palatal (espinha nasal anterior - espinha nasal posterior) em relação a um plano craniométrico fixo e imutável (plano de Frankfourt), que é o plano que passa pelo ponto Pório e pelo ponto Orbital.

Esta medida não representa de forma adequada se a angulação do plano palatal é no sentido horário ou anti-horário, ou seja, se, na inclinação do plano palatal, o ponto ENA está mais próximo do plano de Frankfourt ou se é o ponto ENP que está mais afastado do plano de Frankfourt.

É de fundamental importância no planejamento do tratamento ortopédico, ortodôntico e ou cirúrgico, o conhecimento da correta posição do plano palatal, o qual significa o posicionamento da maxila no sentido rotacional.

Podemos fazer uma correlação entre as variações nas medidas cefalométricas devido à falha na determinação do ponto cefalométrico e às diferenças destas medidas, quando feitas com sobreposição em radiografias de pacientes, antes e após o tratamento ortodôntico, nos levando a considerar se as alterações observadas foram devidas ao resultado do tratamento ortodôntico ou em função das diferenças na identificação dos pontos cefalométricos, como foi relatado por Kamoem, Dermaut e Verbeeck (2001).

Concluímos que as discrepâncias advêm da baixa qualidade da radiografia e da falta de preparo do profissional que vai realizar o traçado, como nos mostra Mori et al. (2001); porém, o que mais contribui para os equívocos, é a falta de precisão na 
localização anatômica dos pontos usados para a análise cefalométrica e, por isso, a necessidade de usarmos pontos que possam variar menos nas avaliações cefalométricas, principalmente aqueles relacionados com a porção anterior da maxila, tanto no plano horizontal como no plano vertical.

Sabemos que os traçados cefalométricos são um auxiliar de recurso terapêutico, definido como exame complementar; assim sendo a anamnese, o exame clínico acurado e a busca por variações anatômicas extrínsecas do paciente devem ser levados em consideração, quando do planejamento individual de cada caso.

A validade do referido exame complementar é diretamente proporcional ao número de informações que este pode nos proporcionais, porém, se tivermos consciência das limitações do método e apoiarmos nossas decisões clínicas, nas alterações observadas no conjunto de informações obtidas, teremos um melhor prognóstico da maioria dos tratamentos que propusermos.

Como sugestão para futuras pesquisas, recomendamos estudos para que se possa traçar um método de avaliação da posição da maxila em relação ao plano palatal, medindo-se a distância entre o ponto ENA perpendicularmente ao plano de Frankfourt e, também o ponto ENP perpendicularmente ao plano de Frankfourt. 


\section{CONCLUSÃO}

Após cuidadosa análise dos resultados e da discussão neste trabalho, podemos concluir que:

7.1 O método de traçado cefalométrico normalmente utilizado, apresenta variação média de $57,5 \%$ na localização anatômica dos pontos cefalométricos, sendo que o traçado cefalométrico é um recurso terapêutico definido como exame complementar, que apresenta muitas variáveis quantitativas.

7.2 O ponto Nasio não apresentou diferenças estatisticamente significantes.

7.3 O ponto espinha nasal anterior não apresentou diferenças estatisticamente significantes.

7.4 Notamos que a dificuldade de localização no ponto A, da ordem de 4,3 mm, implica em alteração na determinação da posição espacial da maxila.

7.5 Os pontos Pogonio, Gnátio e Gônio, não apresentaram diferenças estatisticamente significantes em sua localização. 
7.6 Houve alteração na determinação do ponto Condílio em torno de $2,8 \mathrm{~mm}$. Sua localização depende da identificação do contorno do côndilo na radiografia.

7.7 O ponto ENA mostrou-se o mais reprodutível em nossa análise, com uma diferença estatisticamente não significante.

7.8 Novos estudos deverão ser realizados no sentido de definirmos novas medidas cefalométricas, as quais melhor definam a posição das estruturas que estão envolvidas nos tratamentos ortodônticos, ortopédicos e/ou cirúrgicos. 


\section{REFERÊNCIAS ${ }^{1}$}

Adams JW. Correction of error in cephalometric roentgenograms. Angle Orthod 1940;10(1):3-13.

Amad Neto M. Avaliação da variação nas grandezas cefalométricas obtidas pelo método manual comparada com dois métodos digitais indiretos da análise de Mc Namara [Tese de Mestrado]. São Paulo: Faculdade de Odontologia da USP; 1998.

Amad Neto M, Chilvarquer I. Avaliação da variação nas grandezas cefalométricas obtidas pelo método manual comparada com dois métodos digitais indiretos da análise de Mc Namara. J Bras Ortodon Ortop Facial 2000;5(28):20-7.

Baumrind S, Frantz RC. The reability of head film measurements. Am J Orthod 1971;60(2):111-27.

Bergin R, Hallenberg BR, Malmgren O. Computarized cephalometrics. Acta Odontol Scand 1978;36(6):349-57.

Bolton Fund Head Quarter. First Roentgenographic cephalometric workshop.[Workshop]. Am J Orthod 1958;44(12);899-905.

Broch J, Slagsvold O, Rosler M. Error in landmark identification in lateral radiographic headplates. Eur J Orthod 1981;3(2):9-13.

Brodie AG. The fourth dimension in orthodontia. Angle Orthod 1954;24(1):13-30.

Carlsson GE. Error in x-ray cephalometry. Odontol Tids 1967;75(2):99-129.

\footnotetext{
${ }^{1}$ De acordo com Estilo Vancouver. Abreviatura de periódicos segundo base de dados MEDLINE.
} 
Chen YJ, Chen SK, Chang HF, Chen KC. Comparison of landmark identification in traditional versus computer-aided digital cephalometry. Angle Orthod 2000;70(5):38792.

Davis DN, Mackay F. Reability of cephalometric analysis using manual and interactive computer methods. Br J Orthod 1991;18(2):105-9.

Downs WB. Variations in facial relationships. Their significance in treatment and prognosis. Am J Orthod 1948;34(10):812-40.

Farkas LG, Tompson BD, Katic MJ, Forrest CR. Differences between direct (anthropometric) and indirect (cephalometric) measurements of the skull. J Craniofac Surg 2002;13(1):105-8, disc. 109-10.

Gravely JF, Benzies PM. The clinical significance of tracing error in cephalometry. Br J Orthod 1974;1(3):95-101.

Hagemann K, Vollmer D, Niegel T, Ehmer U, Reuter L. Prospective study on the reproducibility of cephalometric landmarks on convencional and digital lateral headfilms. J Orofac Orthop 2000;61(2):91-9.

Held CL, Ferguson DJ, Gallo MW. Cephalometric digitization: A determination of the minimum scaner settings necessary for precise landmark identification. Am J Orthod Dentofacial Orthop 2001;119(5):472-81

Holdaway RA. Changes in relationship of points $A$ and $B$ during orthodontic treatment. Am J Orthod 1956;42:176-93.

Houston WJB. The analysis of errors in orthodontic measurements. Am J Orthod 1983;83:382-90.

Houston WJB. The application of computer aided digital analysis to orthodontic records. Eur J Orthod 1979;1:71-9.

Houston WJB. A comparision of the reability of measurement of cephalometric radiographs by tracings and direct digitization. Swed Dent J 1982;15:99-103.

Interlandi S. Linha I na análise morfo-diferencial para o diagnóstico ortodôntico. Rev Fac Odontol Univ São Paulo 1971;9(2):289-310. 
Jackson PH, Dickson GC, Birnie DJ. Digital Image Processing of cephalometric radiographs: a preliminary report. Br J Orthod 1985;12:122-32.

Kamoen A, Dermaut L, Verbeeck R. The clinical significance of error measurement in the interpretation of treatment results. Eur J Orthod 2001;23(5):569-78.

Kuan EK. Variability in tracings of lateral head plates for diagnostic orthodontic purposes. Acta Odontol Scand 1969;27(4):259-69.

Liu JK, Chen YT, Cheng HS. Accuracy of computadorized automatic identification of cephalometric landmarks. Am J Orthod Dentofacial Orthop 2000;118(5):535-40.

McNamara Jr JA . A method of cephalometric evaluation. Am J Orthod 1984;86(6):44-69.

Martins LP, Santos-Pinto A, Martins JCR, Dias-Mendes A. Erro de reprodutibilidade das medidas das análises cefalométricas de Steiner e Ricketts, pelo método convencional e método computadorizado. Ortodontia 1995;28(1):4-16.

Miller PA, Savara BS, Singh IJ. Analysis of errors in cephalometric measurement of tree-dimensional distances on the maxilla. Angle Orthod 1966;36(2):169-75.

Mori Y, Miyajima T, Minami K, Sakuda M. An accurate three-dimensional cephalometric system: a solution for the correction of cephalic malpositioning. $\mathrm{J}$ Orthod $2001 ; 28(2): 143-9$.

Nimkarm Y, Miles PG. Reliability of computer-generated cephalometrics. Int J Adult Orthod Orthognath Surg 1995;10(1):43-52.

Phelps AE, Masri N. Location of the apex of the lower central incisor. Am J Orthod Dentofacial Orthop 2000;118(4):429-31.

Richardson A. A comparision of traditional and computerized methods of cephalometric analysis. Eur J Orthod 1981;3:15-20.

Ricketts RM. Analysis, the interim. Angle Orthod 1970;40(2):129-37. 
Ricketts RM, Ruel WB, Hilgers JJ, Schulhof R. An overview of computerized cephalometrics. Am J Orthod 1972;61:1-28.

Riedel RA. An analysis of dento facial relationships. Am J Orthod 1957;43(2):103-19.

Rudolph DJ, Sinclair PM, Coggins JM. Automatic computerized radiographic identification of cephalometric landmarks. Am J Orthod Dentofacial Orthop 1998;113:173-9.

Sander PJ. Reproducibility of cephalometric measurements. Br J Orthod 1988;15:105-10.

Savara BS, Tracy WE, Miller PA. Analysis of errors in cephalometric measurements of three-dimensional distances on the human mandible. Arch Oral Biol 1966;11(2):209-17.

Sicher H, Dubrul E L. Anatomia oral de Sicher e Dubrul. $8^{a}$ ed. São Paulo: Artes médicas; 1991.

Stabrun AE, Danielsen O. Precision in cephalometric landmark identification. Eur J Orthod 1982;4(3):185-96.

Steiner CC. Cephalometrics for you and me. Am J Orthod 1953;39(10):729-55.

Steiner CC. Cephalometrics in clinical pratice. Angle Orthod 1959;29(1):8-29.

Turner PJ, Weerakone S. An evaluation of the reproducibility of landmark identification using scanned cephalometric images. J Orthod 2001;28(3):221-9. 
APÊNDICE A - Dados obtidos nas mensurações cefalométricas

Dados de Nasio perpendicular ponto $\mathrm{A}$

\begin{tabular}{|c|c|c|}
\hline & Rx marcado & Rx não marcado \\
\hline$R x \# 42$ & 7,3 & 4,2 \\
\hline$R x \# 49$ & 9,0 & 9,2 \\
\hline$R x \# 53$ & $-2,2$ & $-3,0$ \\
\hline$R x$ \# 8 & 12,4 & 10,6 \\
\hline$R x \# 96$ & 2,1 & 1,4 \\
\hline$R x \# 963$ & 0,2 & 3,2 \\
\hline$R x \# 101$ & 3,7 & 0,8 \\
\hline$R x \# 107$ & 7,3 & 6,4 \\
\hline$R x \# 127$ & 6,8 & 4,5 \\
\hline$R x \# 136$ & 3,5 & 0,0 \\
\hline$R x \# 137$ & 3,1 & 3,3 \\
\hline$R x \# 153$ & 5,7 & 4,5 \\
\hline$R x \# 158$ & 6,3 & 4,5 \\
\hline$R x \# 187$ & 4,9 & 5,8 \\
\hline
\end{tabular}


Dados de Nasio perpendicular - Pogonio

\begin{tabular}{|c|c|c|}
\hline & Rx marcado & Rx não marcado \\
\hline$R x \# 42$ & 2,1 & 1,0 \\
\hline$R x \# 49$ & 0,3 & 1,2 \\
\hline$R x \# 53$ & $-6,5$ & $-2,4$ \\
\hline$R x \# 58$ & 5,5 & 4,1 \\
\hline$R x \# 96$ & $-7,2$ & $-6,0$ \\
\hline$R x \# 963$ & -4.8 & 0,6 \\
\hline$R x \# 101$ & $-2,8$ & $-7,1$ \\
\hline$R x \# 107$ & 1,7 & 3,5 \\
\hline$R x \# 127$ & $-3,0$ & $-2,1$ \\
\hline$R x \# 136$ & $-3,3$ & $-6,4$ \\
\hline$R x \# 137$ & 2,7 & 3,5 \\
\hline$R x \# 153$ & 7,1 & 10,0 \\
\hline$R x \# 158$ & 2,4 & 1,6 \\
\hline$R x \# 187$ & 0,2 & 0,0 \\
\hline
\end{tabular}

Dados para Condílio - ponto A

\begin{tabular}{|c|c|c|}
\hline & Rx marcado & Rx não marcado \\
\hline$R x \# 42$ & 100,1 & 97,0 \\
\hline$R x \# 49$ & 93,3 & 96,7 \\
\hline$R x \# 53$ & 87,0 & 84,2 \\
\hline$R x \# 58$ & 100.5 & 98,4 \\
\hline$R x \# 96$ & 95.5 & 93,3 \\
\hline$R x \# 963$ & 92.6 & 92,3 \\
\hline$R x \# 101$ & 96.3 & 97,6 \\
\hline$R x \# 107$ & 92,6 & 93,7 \\
\hline$R x \# 127$ & 102,1 & 99,4 \\
\hline$R x \# 136$ & 97,7 & 95,5 \\
\hline$R x \# 137$ & 96,0 & 96,1 \\
\hline$R x \# 153$ & 82,1 & 84,9 \\
\hline$R x \# 158$ & 82,4 & 81,2 \\
\hline$R x \# 187$ & 101,2 & 103,0 \\
\hline
\end{tabular}


Dados para Condílio - Gnátio

\begin{tabular}{|c|c|c|}
\hline & Rx marcado & Rx não marcado \\
\hline$R x \# 42$ & 127,2 & 125,1 \\
\hline$R x \# 49$ & 121,5 & 122,7 \\
\hline$R x \#$ 53 & 117,5 & 120,0 \\
\hline$R x$ 58 & 131,8 & 129,5 \\
\hline$R x \# 96$ & 123,3 & 123,4 \\
\hline$R x \#$ 963 & 120,9 & 120,7 \\
\hline$R x \# 101$ & 133,3 & 135,2 \\
\hline$R x \# 107$ & 122,6 & 123,1 \\
\hline$R x \# 127$ & 131,1 & 131,1 \\
\hline$R x \# 136$ & 134,8 & 133,7 \\
\hline$R x \# 137$ & 126,2 & 129,1 \\
\hline$R x \# 153$ & 119,0 & 117,8 \\
\hline$R x \# 158$ & 93,3 & 93,2 \\
\hline$R x \# 187$ & 124,7 & 126,5 \\
\hline
\end{tabular}

Dados para Espinha Nasal Anterior - Mento

\begin{tabular}{|c|c|c|}
\hline & Rx marcado & Rx não marcado \\
\hline$R x \# 42$ & 77,4 & 77,3 \\
\hline$R x \# 49$ & 76,1 & 74,0 \\
\hline$R x \#$ 53 & 73,2 & 71,1 \\
\hline$R x \# 58$ & 91,8 & 92,9 \\
\hline$R x \#$ 96 & 71,5 & 70,4 \\
\hline$R x \#$ 963 & 71,7 & 71,9 \\
\hline$R x \# 101$ & 91,9 & 89,4 \\
\hline$R x \# 107$ & 70,2 & 70,6 \\
\hline$R x \# 127$ & 83,2 & 80,3 \\
\hline$R x \# 136$ & 82,6 & 83,2 \\
\hline$R x \# 137$ & 74,8 & 74,5 \\
\hline$R x \# 153$ & 67,7 & 67,5 \\
\hline$R x \# 158$ & 51,2 & 52,4 \\
\hline$R x \# 187$ & 68,3 & 69,0 \\
\hline
\end{tabular}


Dados para Nasio - Gnátio

\begin{tabular}{|c|c|c|}
\hline & Rx marcado & $R \times$ não marcado \\
\hline$R x \# 42$ & 137,4 & 139,3 \\
\hline$R x \# 49$ & 128,5 & 128,3 \\
\hline$R x \# 53$ & 122,1 & 121,8 \\
\hline$R x \# 58$ & 144,8 & 143,7 \\
\hline$R x \# 96$ & 125,3 & 124,9 \\
\hline$R x \# 963$ & 125,7 & 125,3 \\
\hline$R x \# 101$ & 147,5 & 147,2 \\
\hline$R x \# 107$ & 124,5 & 126,0 \\
\hline$R x \# 127$ & 136,9 & 132,4 \\
\hline$R x \# 136$ & 144,2 & 142,5 \\
\hline$R x \# 137$ & 126,0 & 123,8 \\
\hline$R x \# 153$ & 121,2 & 120,0 \\
\hline$R x \# 158$ & 91,7 & 91,6 \\
\hline$R x \# 187$ & 125,4 & 120,3 \\
\hline
\end{tabular}

Dados para Nasio - Espinha Nasal Anterior

\begin{tabular}{|c|c|c|}
\hline & Rx marcado & Rx não marcado \\
\hline$R x \# 42$ & 64,4 & 64,4 \\
\hline$R x \# 49$ & 55,2 & 53,9 \\
\hline$R x \#$ 53 & 50,0 & 51,1 \\
\hline$R x \# 58$ & 56,1 & 57,0 \\
\hline$R x \# 96$ & 56,9 & 56,7 \\
\hline$R x \#$ 963 & 56,3 & 56,0 \\
\hline$R x \# 101$ & 56,0 & 54,8 \\
\hline$R x \# 107$ & 58,5 & 58,3 \\
\hline$R x \# 127$ & 56,1 & 56,4 \\
\hline$R x \# 136$ & 62,1 & 61,8 \\
\hline$R x \# 137$ & 53,6 & 53,0 \\
\hline$R x \# 153$ & 55,3 & 54,9 \\
\hline$R x \# 158$ & 91,0 & 91,2 \\
\hline$R x \# 187$ & 59,2 & 60,0 \\
\hline
\end{tabular}




\section{Faculdade de Odontologia}

\section{Universidade de São Paulo}

PARECER $n^{\circ} 161 / 03$

Protocolo 166/03

O Grupo de Trabalho indicado pelo Comitê de Ética em Pesquisa, APROVOU o protocolo de pesquisa "Estudo da padronização para determinação de pontos cefalométricos utilizados na cefalometria radiológica", de responsabilidade do pesquisador Mustaphá Amad Neto.

Tendo em vista a legislação vigente, devem ser encaminhados a este Comitê relatórios anuais referentes ao andamento da pesquisa e ao término cópia do trabalho em "cd". Qualquer emenda do projeto original deve ser apresentada a este CEP para apreciação, de forma clara e sucinta, identificando a parte do protocolo a ser modificada e suas justificativas.

São Paulo, 26 de setembro de 2003. 